Review

\title{
Sun Glint Correction of High and Low Spatial Resolution Images of Aquatic Scenes: a Review of Methods for Visible and Near-Infrared Wavelengths
}

\author{
Susan Kay ${ }^{1} *$, John D. Hedley ${ }^{1}$ and Samantha Lavender ${ }^{2,3}$
}

1 Marine Spatial Ecology Lab, School of Biosciences, Hatherly Laboratory, Prince of Wales Road, University of Exeter, Exeter, Devon, EX4 4PS, UK; E-Mail: J.D.Hedley@exeter.ac.uk

2 ARGANS Ltd, Tamar Science Park, Plymouth, Devon, PL6 8BY, UK; E-Mail: SLavender@argans.co.uk

3 School of Marine Science and Engineering, University of Plymouth, Drakes Circus, Plymouth, Devon, PL4 8AA, UK

* Author to whom correspondence should be addressed; E-Mail: sk284@exeter.ac.uk; Tel.: +44-1392-263757; Fax: +44-1392-263700.

Received: 4 August 2009; in revised form: 1 September 2009 / Accepted: 21 September 2009 / Published: 12 October 2009

\begin{abstract}
Sun glint, the specular reflection of light from water surfaces, is a serious confounding factor for remote sensing of water column properties and benthos. This paper reviews current techniques to estimate and remove the glint radiance component from imagery. Methods for processing of ocean color images use statistical sea surface models to predict the glint from the sun and sensor positions and wind data. Methods for higher resolution imaging, used in coastal and shallow water mapping, estimate the glint radiance from the near-infrared signal. The effects of some current methods are demonstrated and possibilities for future techniques are briefly addressed.
\end{abstract}

Keywords: sun glint; sun glitter; ocean color; coral reef; bathymetry; shallow water

\section{Introduction}

Remote sensing of oceans and coastal zones is a key technology for monitoring environmental change, facilitating conservation of natural resources and understanding global carbon budgets and climate change impacts. Global estimations of chlorophyll concentration and monitoring of 
phytoplankton blooms have been supported by a number of marine-specific satellite missions for the visible wavelength range, including SeaWiFS, MERIS and the planned Ocean and Land Colour Imager. In shallow waters, mapping benthic cover of macroalgae, seagrasses, or coral reefs from satellites or airborne sensors is an important aim for environmental conservation and assessment of anthropogenic disturbance. In all applications, one of the greatest confounding factors limiting the quantity and accuracy of remotely sensed data from water bodies is sun glint, the specular reflection of directly transmitted sunlight from the upper side of the air-water interface (Figure 1).

Figure 1. Illustration of sun glint in a variety of optical imagery. See Table 1 for sensor information. (a)(i) Sub-set of a MERIS image of the Pacific Ocean, showing sun glint on the right hand side. (a)(ii) Sensor radiance plotted for 4 wavebands along the line marked in (a) (i). (b)(i) IKONOS image of Glovers Reef, Belize, showing glint from waves in the lower right part of the image, with bright peaks corresponding to individual waves. (b)(ii) Sensor radiance plotted for 4 wavebands along the line marked in (b)(i). (c)(i) Cross-track glint in a CASI image of Plymouth Sound (UK); showing glint on the left hand side. (c)(ii) Sensor radiance plotted for 4 wavebands along the line marked in (c)(i).

(a) (i)

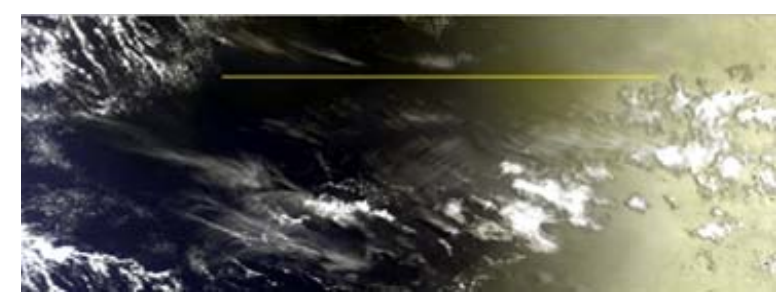

(b) (i)

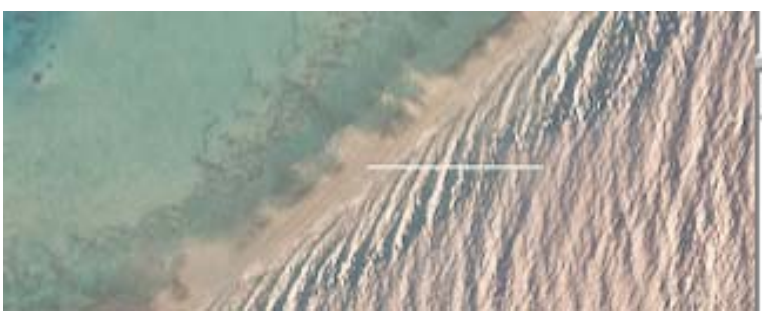

(c) (i)

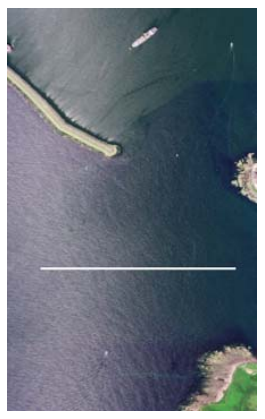

(a) (ii)

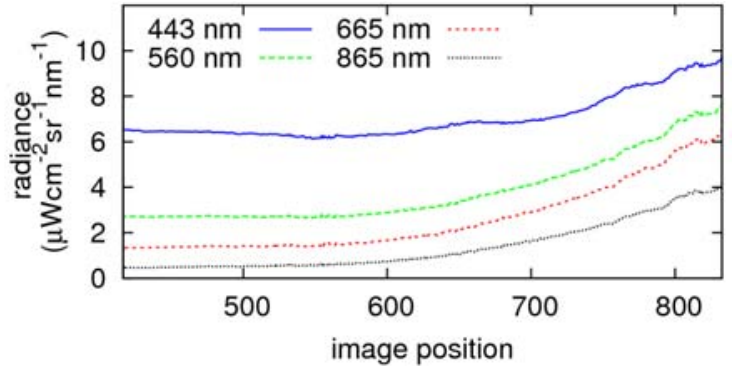

(b) (ii)

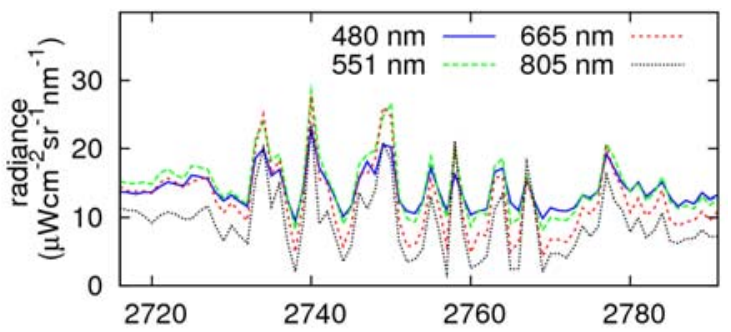

(c) (ii)

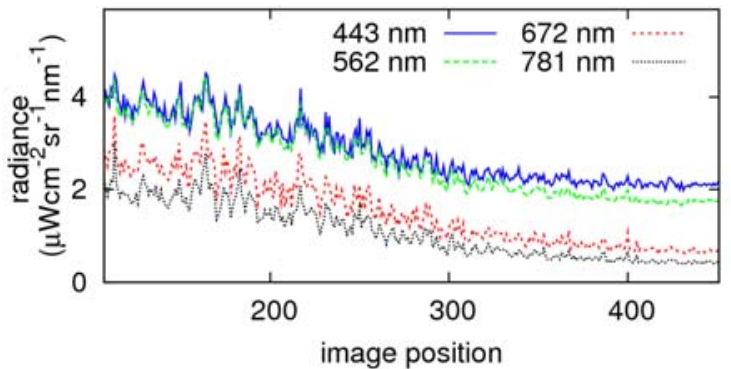

Sun glint occurs in imagery when the water surface orientation is such that the sun is directly reflected towards the sensor; and hence is a function of sea surface state, sun position and viewing angle. The component of sensor-received radiance due to specular reflection of light from the water 
surface can be much greater than the water-leaving radiance from sub-surface features. In this situation retrieval of information such as chlorophyll content, benthic features or bathymetry requires both high measurement sensitivity and a robust algorithm that can separate and remove the effect of glint.

Imagery lost to sun glint represents a considerable cost both financially and scientifically. In a case study by Goodman et al. [1], uncorrected glint in high resolution imagery led to errors as large as 30\% in the measurement of water depth. Hochberg et al. [2] reported that in a set of 45 IKONOS images of coral reefs purchased by the National Aeronautics and Space Administration, 9 were badly contaminated by glint, and 13 more had significant areas of glint (Figure 1b). For the Medium Resolution Imaging Spectrometer (MERIS) glint-contaminated pixels are masked, causing complete loss of the affected pixels: this affects almost half the observations at sub-tropical latitudes [3]. In the case of airborne surveys, glint can be reduced by optimally choosing the flight direction and time of day, but the images can still be contaminated (Figure 1c). With IKONOS images costing \$US10-64 per square kilometer (Eurimage S.p.a and MapMart.com, April 2009), sun glint contamination can cause substantial financial as well as data loss.

A variety of glint correction methods have been developed for open ocean imaging and higher resolution coastal and aerial applications. In all cases the principle is to estimate the glint contribution to the radiance reaching the sensor, and then subtract it from the received signal. The methods fall into two categories:

- Methods of the first category are used for open ocean imagery with resolutions on the scale of 100-1,000 m. Statistical models of the sea surface, such as that of Cox and Munk [4,5], are used to calculate the probability that the sea surface will be orientated to cause glint, depending on the wind speed and direction. This probability is then used to predict the amount of glint for a given wind vector, sun and sensor position. Variations on this method are used for a number of operational ocean color instruments [6-8]. However, they can only correct moderate glint and large errors remain in the brightest glint areas.

- A separate set of methods is used for coastal images with pixel sizes less than about $10 \mathrm{~m}$. These use data from the near-infrared (NIR) to give an indication of the amount of glint in the received signal. This is based on the assumption that the water-leaving radiance in this part of the spectrum is negligible and so any NIR signal remaining after atmospheric correction must be due to sun glint. The spectrum for a deep water part of the image is examined and used to establish the relationship between the NIR and glint radiances $[1,2,9,10]$. These methods can improve data retrieval for bathymetry or habitat classification, but the assumption of no waterleaving radiance in the NIR is not valid for very shallow or turbid water or where vegetation reaches the surface.

This paper reviews both approaches to sun glint correction techniques. Section 2 discusses the theoretical background of glint formation and avoidance. Section 3 gives a summary of current glint correction techniques and Sections 4 and 5 describe the two types of method in more detail. Sections 6 and 7 briefly cover glint at non-visible wavelengths and possible uses of glint-derived information. Finally the potential for improvement of current techniques is discussed, with a brief outline of some possible future developments. 
Table 1. Summary of radiometry instruments mentioned in this review.

\begin{tabular}{|c|c|c|c|c|c|}
\hline Instrument name & Dates in orbit & Satellite & Band information & Tilting? & $\begin{array}{l}\text { Resolution } \\
\text { (m) }\end{array}$ \\
\hline $\begin{array}{l}\text { Sea-viewing Wide Field- } \\
\text { of-view Sensor } \\
(\text { SeaWiFS) }[11]\end{array}$ & 1997-present & $\begin{array}{l}\text { OrbView-2 } \\
\text { (also called } \\
\text { SeaStar) }\end{array}$ & $\begin{array}{l}8 \text { bands in the visible } \\
\text { and NIR }\end{array}$ & $\mathrm{Y}$ & $1100 / 4500$ \\
\hline Global Imager (GLI) [12] & $2002-2003$ & ADEOS-II & $\begin{array}{l}36 ; 23 \text { in visible and } \\
\text { near-infrared }\end{array}$ & Y & 1000 \\
\hline $\begin{array}{l}\text { Medium Resolution } \\
\text { Imaging Spectrometer } \\
\text { (MERIS) [13] }\end{array}$ & 2002-present & Envisat & $\begin{array}{l}15 \text {, ranging from } 412.5 \text { to } \\
900 \mathrm{~nm}\end{array}$ & $\mathrm{~N}$ & $300 / 1200$ \\
\hline $\begin{array}{l}\text { Moderate Resolution } \\
\text { Imaging } \\
\text { Spectroradiometer } \\
\text { (MODIS) [14] }\end{array}$ & $\begin{array}{l}1999 \text { (Terra) } \\
\text { /2002 (Aqua) } \\
\text {-present }\end{array}$ & $\begin{array}{l}\text { Aqua (EOS } \\
\text { PM) \& } \\
\text { Terra (EOS } \\
\text { AM) }\end{array}$ & $\begin{array}{l}36 ; 8 \text { bands in the visible } \\
\text { and NIR are used for ocean } \\
\text { colour, other bands extend } \\
\text { up to } 14 \mu \mathrm{m}\end{array}$ & $\mathrm{N}$ & 1000 \\
\hline $\begin{array}{l}\text { IKONOS multispectral } \\
\text { imager [15] }\end{array}$ & 1999-present & IKONOS & $\begin{array}{l}4 \text { bands, visible and NIR, } \\
\text { each about } \\
70-100 \mathrm{~nm} \text { wide }\end{array}$ & $\mathrm{N}$ & 4 \\
\hline $\begin{array}{l}\text { Airborne Visible/Infrared } \\
\text { Imaging Spectrometer } \\
\text { (AVIRIS) [16] }\end{array}$ & $\begin{array}{l}\text { Flights since } \\
1992\end{array}$ & $\begin{array}{l}\text { Airborne, } \\
20 \mathrm{~km} \\
\text { altitude }\end{array}$ & $\begin{array}{l}224 \text { bands, visible to } \\
\text { infrared }(400-2,500 \mathrm{~nm})\end{array}$ & $\mathrm{N}$ & 20 \\
\hline $\begin{array}{l}\text { Compact Airborne } \\
\text { Spectral Imager-2 } \\
(\text { CASI-2)* }[17]\end{array}$ & $\begin{array}{l}\text { Flights since } \\
1989\end{array}$ & Airborne & $\begin{array}{l}18-288 \text { band in the range } \\
405-950 \mathrm{~nm} \text {, number of } \\
\text { bands and band frequencies } \\
\text { are tunable }\end{array}$ & $\mathrm{N}$ & $<1-10$ \\
\hline $\begin{array}{l}\text { Coastal Zone Color } \\
\text { Scanner (CZCS) [18] }\end{array}$ & 1978-1986 & Nimbus 7 & $\begin{array}{l}6 \text { Band centres: } 443,520, \\
550,670,750,11500\end{array}$ & Y & 825 \\
\hline $\begin{array}{l}\text { Ocean color and } \\
\text { Temperature Sensor } \\
\text { (OCTS) }[19]\end{array}$ & 1996-1997 & ADEOS & $\begin{array}{l}12 ; 8 \text { bands in visible and } \\
\text { near-infrared }\end{array}$ & $\mathrm{Y}$ & 700 \\
\hline $\begin{array}{l}\text { Polarization and } \\
\text { Directionality of the } \\
\text { Earth's Reflectances } \\
\text { (POLDER) [20] }\end{array}$ & $\begin{array}{l}1996-1997 \\
2002-2003\end{array}$ & $\begin{array}{l}\text { ADEOS } \\
\text { ADEOS-II }\end{array}$ & $\begin{array}{l}8,443,490,565,665,763 \\
765,865 \text { and } 910\end{array}$ & $\mathrm{~N}$ & 7000 \\
\hline $\begin{array}{l}\text { Ocean and Land Colour } \\
\text { Instrument (OCLI) [21] }\end{array}$ & $\begin{array}{l}\text { Due for launch } \\
\text { in } 2012\end{array}$ & Sentinel-3 & $21,400-1,020 \mathrm{~nm}$ & Y & $300 \mathrm{~m}$ \\
\hline
\end{tabular}

* Other CASI models also exist

\section{Theoretical Background}

This section reviews the process by which sun glint appears in aquatic imagery, and shows how this leads to avoidance strategies where practical. 


\subsection{Radiative Transfer Processes}

The radiance reaching a remote sensing detector can arrive by a number of routes. Five key processes are shown in Figure 2.

Figure 2. Schematic diagram showing routes by which light can reach a remote sensing detector.

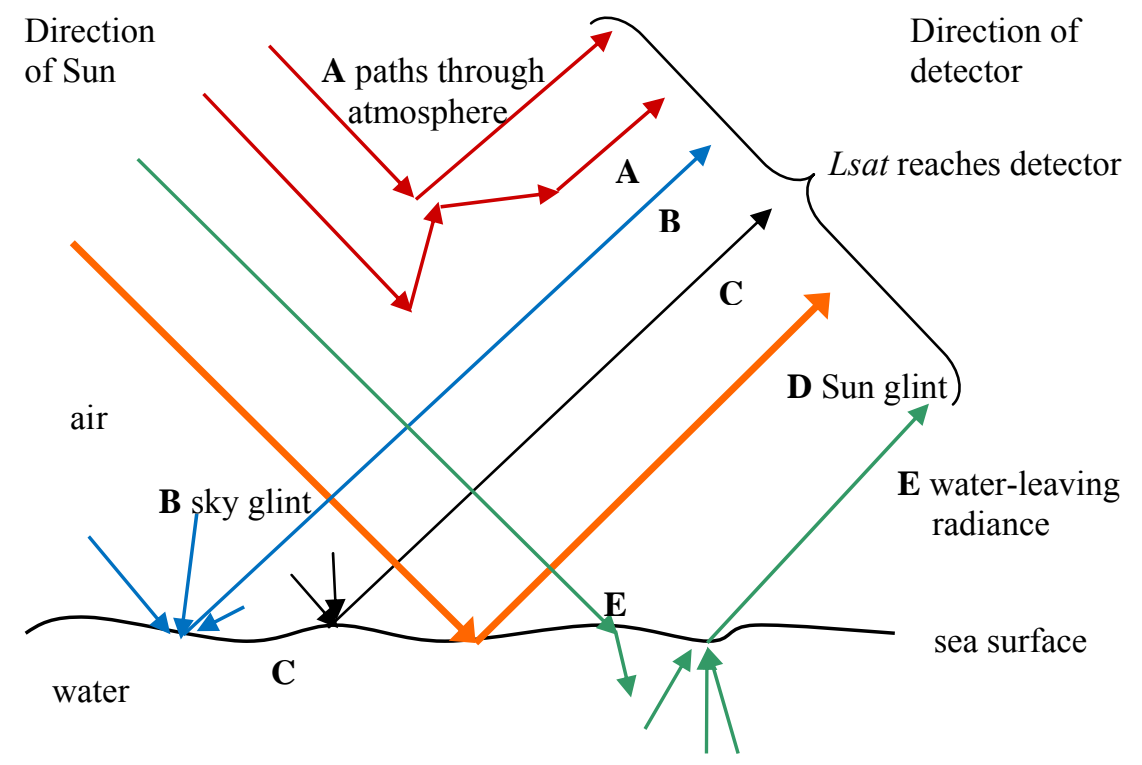

A Single or multiple scattering in the atmosphere, by molecules or aerosols

B Scattering from the atmosphere to the water surface and then reflection to the detector-often termed "sky glint"

$\longrightarrow$ C Reflection from whitecaps on the sea surface

$\longrightarrow$ D Specular reflection from water surface, with direct transmission through the atmosphere from the sun to the surface and from the surface to the detector - this is termed 'sun glint' in the context of this review.

E Transmission through the atmosphere and air-water interface followed by scattering or reflection below the water surface and transmission back through the atmosphere to the detector.

If these five processes are assumed to be predominantly responsible for the sensor-received signal then:

$$
L_{\text {sensor }}=L_{\text {atm }}+T L_{\text {sky }}+T L_{\text {whitecap }}+T L_{\text {glint }}+T L_{\text {water }}
$$

where $T$ is the transmittance of the atmosphere along the sensor view direction, the path radiance $L_{\mathrm{atm}}$ is the radiance arriving at the sensor via atmospheric paths (A) and $L_{\text {sky }}, L_{\text {whitecap }}, L_{\text {glint }}$ and $L_{\text {water }}$ are the radiances just above the water surface for light travelling by the sky glint, whitecap, sun glint and water-leaving routes in Figure 2 (see also Table 2). All these terms depend on the wavelength and other factors - fuller details are given in Sections 4 and 5.

Of the terms in Equation 1, $L_{\text {water }}$ contains the information about water column and benthic features, and must be separated from the other terms if this information is to be retrieved. This paper reviews 
methods to estimate and remove $T L_{\text {glint }}$. Techniques to correct for the other terms are also needed, but are beyond the scope of this review. Note in particular that sky glint, where light is not incident from the solar direction, is not removed by the methods described here and must be treated separately.

Table 2. Nomenclature used in equations.

\begin{tabular}{|c|c|}
\hline$L_{\text {sensor }}$ & total radiance reaching a sensor \\
\hline$L_{\text {atm }}$ & radiance reaching the sensor via single or multiple scattering in the atmosphere (path radiance) \\
\hline$L_{\text {glint }}$ & $\begin{array}{l}\text { radiance just above the water surface for light reaching the sensor by specular reflection at the } \\
\text { surface and direct transmission through the atmosphere: sun glint }\end{array}$ \\
\hline$L_{\text {sky }}$ & $\begin{array}{l}\text { radiance just above the water surface for light scattered from the atmosphere and then reflected from } \\
\text { the water surface to the sensor ("sky glint") }\end{array}$ \\
\hline$L_{\text {whitecap }}$ & radiance just above the water surface for light reflected from whitecaps on the water surface \\
\hline$L_{\text {water }}$ & $\begin{array}{l}\text { radiance just above the water surface for light transmitted into the water and then scattered or } \\
\text { reflected to the sensor }\end{array}$ \\
\hline$L_{\text {Rayleigh }}$ & radiance reaching the sensor due to Rayleigh scattering from molecules in the atmosphere \\
\hline$L_{\text {aerosol }}$ & radiance reaching the sensor due to scattering from aerosols in the atmosphere \\
\hline$L_{\mathrm{ra}}$ & radiance reaching the sensor due to Rayleigh-aerosol interaction \\
\hline$L_{G N}$ & $\begin{array}{l}\text { normalized sun glint radiance, used in the SeaWiFS scheme: the glint radiance that would be } \\
\text { received if there was no atmosphere and the solar irradiance were } 1 \text { (Equation 26) }\end{array}$ \\
\hline$F_{o}(\lambda)$ & the extraterrestrial solar irradiance \\
\hline$T_{o}(\lambda)$ & the atmospheric direct transmittance along the path from the sun to the water surface \\
\hline $\begin{array}{l}T(\lambda) \\
t(\lambda)\end{array}$ & $\begin{array}{l}\text { direct and diffuse transmittance of the atmosphere between the water surface and the sensor, i.e., the } \\
\text { proportion of the radiance leaving the surface that reaches the sensor; diffuse transmittance includes } \\
\text { light scattered into the path. }\end{array}$ \\
\hline$\omega, \omega^{\prime}$ & the angle of incidence and refraction of a light ray at the water surface \\
\hline$\beta, \gamma$ & steepest slope and azimuth of a facet of the water surface \\
\hline$\theta_{s,} \varphi_{s}$ & solar zenith and azimuth angles \\
\hline$\theta_{V}, \varphi_{V}$ & sensor zenith and azimuth angles \\
\hline$x, y, z$ & $\begin{array}{l}\text { a right-handed axis system with } x \text { in the downwind direction, } y \text { in the crosswind direction and } z \\
\text { vertically upwards from the equilibrium position of the sea surface }\end{array}$ \\
\hline$Z_{X} Z_{y}$ & facet slope $\partial z / \partial x, \partial z / \partial y$ \\
\hline$E$ & solar irradiance at the surface \\
\hline$\rho(\omega, \lambda)$ & Fresnel reflectance at the water surface \\
\hline$p\left(Z_{X}, Z_{y}\right)$ & probability distribution function of the sea surface slope \\
\hline$\sigma_{W}, \sigma_{c}$ & root mean square slopes in the downwind and crosswind directions \\
\hline$\xi \eta$ & normalized surface slopes $z_{x} / \sigma_{w}$ and $z_{y} / \sigma_{c}$ \\
\hline mss & mean square slope (of the sea surface) \\
\hline$U_{10}$ & the wind speed at $10 \mathrm{~m}$ above mean sea level \\
\hline$W$ & surface wind vector, measured at $10 \mathrm{~m}$ \\
\hline$\tau_{\text {aerosol, }}$ & the aerosol and Rayleigh optical thicknesses of the atmosphere \\
\hline$\tau_{\text {Rayleigh }}$ & \\
\hline
\end{tabular}


For normal non-glint conditions the radiance received by a satellite-borne sensor is dominated by atmospheric scattering-light from paths through the air make up over $80 \%$ of received radiance, with water-leaving paths contributing around $15 \%$ and reflected light just $1 \%-2 \%$ (Table 3, [22]). The examples in Figure 1 show how glint can increase the reflected radiance by a factor of 2 or more-since the water-leaving radiance remains the same its percentage contribution falls, and so a high signal-to-noise ratio is required if this component is to be distinguished from the atmospheric signal. In the worst cases glint can saturate the sensor, so that water-leaving radiance cannot be retrieved for those pixels.

Table 3. Contribution to sensor signal from various routes in non-glint conditions (from [22]).

\begin{tabular}{|c|c|c|c|c|c|c|}
\hline \multirow{3}{*}{$\begin{array}{l}\text { Wavelength } \\
(\mathrm{nm})\end{array}$} & \multicolumn{6}{|c|}{$\%$ contribution to received signal } \\
\hline & \multicolumn{3}{|c|}{ Clear water } & \multicolumn{3}{|c|}{ Turbid water } \\
\hline & $\begin{array}{l}\text { Air paths } \\
\text { (A) }\end{array}$ & $\begin{array}{l}\text { Reflected paths } \\
\text { (C and D) }\end{array}$ & $\begin{array}{l}\text { Water-leaving } \\
\text { paths (E) }\end{array}$ & $\begin{array}{l}\text { Air paths } \\
\text { (A) }\end{array}$ & $\begin{array}{l}\text { Reflected paths } \\
\text { (C and D) }\end{array}$ & $\begin{array}{l}\text { Water-leaving } \\
\text { paths (E) }\end{array}$ \\
\hline 440 & 84.4 & 1.2 & 14.4 & 80.8 & 1.1 & 18.1 \\
\hline 520 & 81.2 & 1.3 & 17.5 & 66.6 & 1.1 & 32.3 \\
\hline 550 & 84.2 & 1.3 & 14.5 & 64.1 & 1.0 & 34.9 \\
\hline 670 & 96.3 & 1.5 & 2.2 & 82.4 & 1.2 & 16.4 \\
\hline 750 & 97.0 & 1.9 & 1.1 & 97.4 & 1.5 & 1.1 \\
\hline
\end{tabular}

Note that the separation of radiance by source, shown in Equation 1, can only be used in practice if photons arriving by the different routes can be distinguished. This could be done by using a model of each process to predict the received radiance, or by using cross-band information and an understanding of the spectral differences produced by each process. For example, water is a good absorber of NIR radiation [23], so the water-leaving radiance is often assumed to be zero for these wavelengths [2,24]. However, this may not be true if the water is shallow or turbid [25,26]. It is particularly difficult to distinguish between sun glint and light scattered by aerosols, i.e., particles suspended in the air, for two reasons:

- both processes have only a weak dependence on wavelength, so do not leave a distinctive spectral signature. The wavelength dependence of sun glint is through variation in the refractive index (see Equations 12 and 28) - for pure water this varies from 1.339 at $400 \mathrm{~nm}$ to 1.328 at $900 \mathrm{~nm}$ [27], while for sea water it varies from 1.35 at $400 \mathrm{~nm}$ to 1.34 at $700 \mathrm{~nm}$ [28]. The aerosol reflectance varies as $\lambda^{\alpha}$, where $\alpha$ is the Angström exponent, whose value varies from about +1 to -2 depending on environmental conditions [26]. Typical maritime values are 0.3-1.0 [29]; for low values, corresponding to large aerosols, the wavelength dependence is weak.

- the atmospheric transmittance, $T$, depends on aerosol scattering, so the radiance term $T L_{\mathrm{glint}}$ inevitably involves both glint and aerosol processes. Without knowing the concentration and size of aerosol in the path $T$ cannot be calculated; the aerosol quantities can vary significantly over time scales of days and space scales of a few kilometers [26]. 


\subsection{Geometric Estimation and Prediction of Sun Glint}

This section shows how the amount of sun glint can be predicted using the laws of reflection, knowledge of the solar and sensor position and a statistical model of the sea surface. This means that remote sensing missions can be planned to avoid the worst glint, and in principle allows the glint radiance to be calculated and subtracted from the received signal.

If the surface is perfectly flat the reflection of the sun appears as a very bright, relatively small portion of the sea surface. If the wind is stronger and the sea surface correspondingly less smooth, parts of the water surface further from the centre of the sun glint pattern will be at the required orientation to reflect sun light to the viewer, so the sun's reflection covers a larger area of the surface and is made of many tiny highlights, each a reflection of the sun from a particular point on the surface. The brightness of each pixel equals the total brightness of all highlights in that pixel, and hence is proportional to the fraction of the sea surface at the right slope.

Initially the sun and sensor are treated as a point source and point receiver. For a given position of the source and receiver there is only one slope and orientation of the water surface which will reflect incident sun light into the measuring instrument. The geometry shown in figure 3 is used to establish the link between solar, viewing and water surface positions.

Figure 3. Sun glint geometry. Light from the sun, travelling along vector I, is reflected by the water surface to the satellite in the direction R. The normal to the water surface is $\mathbf{n} . X$, $y$ and $z$ form a right-handed axis system, with the $z$-axis vertically upwards from the mean position of the sea surface. The choice of $x$-direction is arbitrary-in this paper $x$ is taken as downwind. Zenith angles are measured from the $z$-axis, azimuth angles clockwise from the $x$-axis in the $x-y$ plane. The steepest slope of the water surface facet is $\beta$, at azimuth $\gamma$.

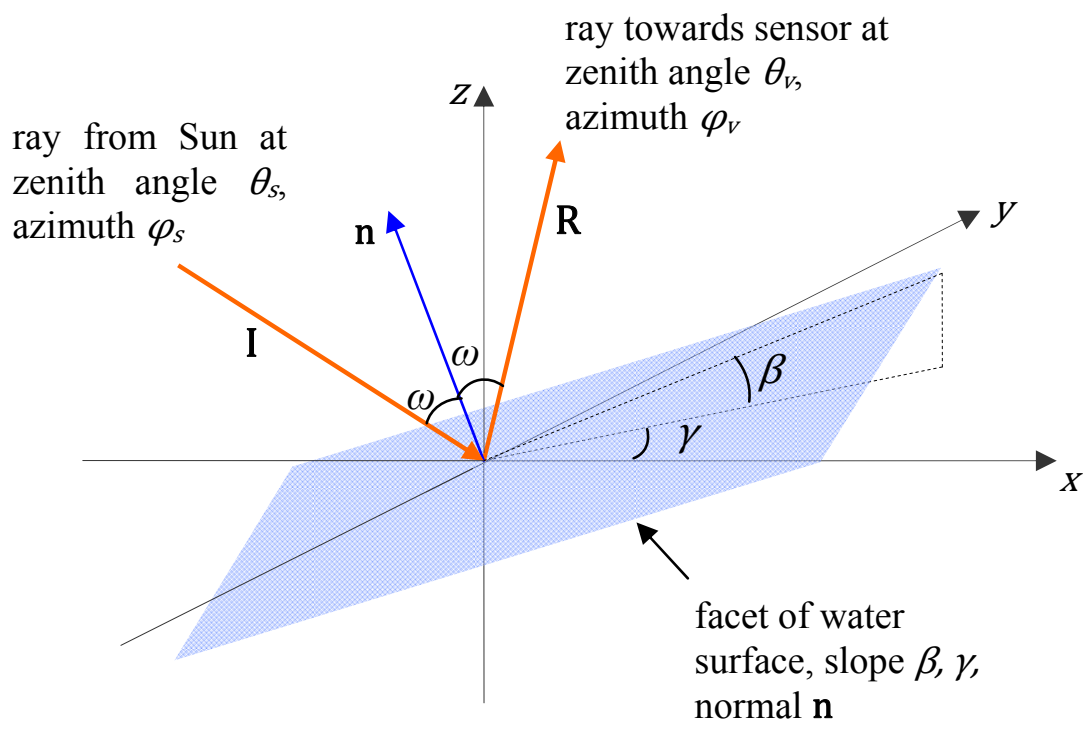

In the visible and NIR the wavelength of light is much shorter than the surface waves, so the incident light can be treated as a ray meeting a flat surface, at an angle $\omega$ with the normal $\mathbf{n}$ to the 
surface. By the laws of reflection, it must be reflected at the same angle and the incident and reflected rays and the normal must lie in the same plane. Therefore, if $I$ and $R$ are unit vectors in the direction of the incident and reflected light:

$$
\mathbf{R}-\mathbf{I}=2 \cos \omega \mathbf{n}
$$

By setting the components equal on each side of this equation it can be shown that [for example 6,7]:

$$
\begin{gathered}
\cos 2 \omega=\sin \theta_{s} \sin \theta_{v} \cos \left(\varphi_{s}-\varphi_{v}\right)+\cos \theta_{s} \cos \theta_{v} \\
\cos \beta=\frac{\cos \theta_{s}+\cos \theta_{v}}{2 \cos \omega} \\
\cos \gamma=-\frac{\sin \theta_{s} \cos \varphi_{s}+\sin \theta_{v} \cos \varphi_{v}}{2 \cos \omega \sin \beta} \\
\sin \gamma=-\frac{\sin \theta_{s} \sin \varphi_{s}+\sin \theta_{v} \sin \varphi_{v}}{2 \cos \omega \sin \beta}
\end{gathered}
$$

The facet slope is given by:

$$
\begin{aligned}
& \frac{\partial z}{\partial x}=z_{x}=\tan \beta \cos \gamma \\
& \frac{\partial z}{\partial y}=z_{y}=\tan \beta \sin \gamma
\end{aligned}
$$

Combining Equations (7) and (8) with the results of (3) to (6) gives:

$$
\begin{gathered}
z_{x}=-\frac{\sin \theta_{s} \cos \varphi_{s}+\sin \theta_{v} \cos \varphi_{v}}{\cos \theta_{s}+\cos \theta_{v}} \\
z_{y}=-\frac{\sin \theta_{s} \sin \varphi_{s}+\sin \theta_{v} \sin \varphi_{v}}{\cos \theta_{s}+\cos \theta_{v}}
\end{gathered}
$$

Thus for a given viewing geometry, if the sun and sensor are treated as a point source and detector there is only one facet slope and orientation that is consistent with specular reflection. In reality the sun has an angular diameter of $0.53^{\circ}$, so there will be a range of possible slopes that can reflect light from some part of the sun's disc into the sensor. Cox and Munk [30] define the "tolerance ellipse" in $Z_{x} Z_{y}$ space as the range of slopes from which light can be reflected from some part of the sun's disc into the sensor. They show that the area of the tolerance ellipse is:

$$
\Delta_{t}=1 / 4 \pi \varepsilon^{2} \sec ^{3} \beta \sec \omega
$$

where $\varepsilon$ is the angular radius of the sun, provided that the solid angle subtended by light from the highlight at the sensor is much less than that subtended by the sun $\left(\pi \varepsilon^{2}\right)$ - this is true because each highlight reflects light from only a small part of the sun's disc.

If the areas of the sea surface under consideration are large enough to contain the full range of slopes and many highlights the received radiance can be treated statistically, as the sum of highlights from different slopes and different parts of the surface. A probability distribution function (PDF) $p\left(z_{x o}\right.$, $z_{y o}$ ) for the sea surface slope is defined as the probability of the slope being in the interval $z_{x o} \pm 1 / 2 \delta z_{x}$, $z_{y o} \pm 1 / 2 \delta z_{y}$ is $p\left(z_{x o}, Z_{y o}\right) \delta z_{x} \delta z_{y}$. Then the probability of a slope lying within the tolerance ellipse 
centered on $Z_{x o}, Z_{y o}$ is $p\left(Z_{x o}, Z_{y o}\right) \Delta_{\mathrm{t}}$-this is proportional to the brightness of the highlight from $Z_{x o}, Z_{y o}$. By adding the contributions from all highlights at a given slope and then from all slopes it can be shown [5] that the received radiance will be:

$$
L=\frac{E \rho(\omega, \lambda) p\left(z_{x}, z_{y}\right)}{4 \cos ^{4} \beta \cos \theta_{v}}
$$

where $L$ is the radiance towards the sensor, $E$ the solar irradiance at the surface and $\rho(\omega, \lambda)$ the Fresnel reflectance at the surface. Since $Z_{x}, Z_{y}$ and $\beta$ are functions of the solar and sensor geometry the glint radiance can be predicted if the probability distribution function of surface slopes is known - this is considered in section 3.1.

\subsection{Avoidance of Sun Glint}

The most straightforward way to deal with the sun glint problem is to avoid it by an appropriate choice of place and time for image acquisition. Many satellite-borne instruments, for example SeaWiFS, OCTS and CZCS, can tilt $20^{\circ}$ from nadir to minimize sun glint $[6,31,32]$. The tilt is operationally adjusted to $+20^{\circ}, 0$ or $-20^{\circ}$ to avoid reflected sunlight [33]. The European Space Agency's MERIS follow-on, Ocean and Land Colour Imager (OLCI) on Sentinel-3, will also tilt to avoid glint [21]. However, for satellite-borne sensors that do not have a tilting capability, e.g., MERIS and MODIS (Table 1), this avoidance strategy is not possible. High-resolution sensors such as IKONOS and Quickbird are useful for coastal and reef studies, e.g., [2,9,34], but their missions are primarily targeted for land observation and so neglect identification or avoidance of aquatic glint.

For airborne instruments, the flight path can be chosen to minimize glint. Push-broom sensors such as the Compact Airborne Spectral Imager (CASI) need to avoid glint across the track, so flight paths towards or away from the sun with solar zenith angles of $30^{\circ}-60^{\circ}$ are recommended $[35,36]$. Numerical simulations of radiative transfer suggest that a viewing angle of $40^{\circ}$ from nadir and $135^{\circ}$ from the sun is optimal for avoiding glint [37]. For CASI, flying towards the sun gives a reasonable approximation to this, with viewing angles from nadir out to $\pm 37^{\circ}$ and $90^{\circ}$ from the sun, but this will not be enough to avoid all glint. Other constraints may prevent optimal sensor orientation, for example some Lidar bathymetry systems carry hyperspectral imagers and in this case the flight path may be determined by the needs of the bathymetry acquisition [38].

Aerial cameras have a smaller field of view, but can still suffer from similar problems. Mount [39] gives a method of predicting the latest time of day at which aerial photography can be done at a particular location without the risk of excessive glint. Flying early in the morning means that the sun is low and the reflection angle (for a flat sea) is greater than the viewing zenith angle - the reflected light passes under the field of view of the sensor. When the sea is rough light is scattered towards the sensor for lower solar elevation, and hence earlier in the day, than for calm sea. Mount's method uses sun angle, sensor field of view and wind speed, from which a glint prediction can be made based on a simplified model of the sea surface state.

Thus correction methods are needed for a range of satellite and airborne instruments which are unable to avoid glint in at least part of their field of view. 


\section{Summary of Current Glint Correction Techniques}

Published glint correction methods are summarized in Table 4 with the two types of method discussed further in Sections 4 and 5.

Table 4. Summary of sun glint correction methods.

\begin{tabular}{|c|c|c|c|c|c|c|}
\hline $\begin{array}{l}\text { Method } \\
\text { type }\end{array}$ & $\begin{array}{l}\text { Authors and } \\
\text { ref. }\end{array}$ & $\begin{array}{l}\text { Demonstration } \\
\text { instrument }\end{array}$ & Outline of method & Assumptions & $\begin{array}{l}\text { Examples } \\
\text { of use }\end{array}$ & $\begin{array}{l}\text { Before/after } \\
\text { atmospheric } \\
\text { correction }\end{array}$ \\
\hline Open ocean & $\begin{array}{l}\text { Wang \& } \\
\text { Bailey [6] } \\
\text { Wang et al. } \\
\text { [31] }\end{array}$ & $\begin{array}{l}\text { POLDER } \\
\text { OCTS }\end{array}$ & $\begin{array}{l}\text { Glint is predicted from } \\
\text { wind speed (NCEP data) } \\
\text { and subtracted from } \\
\text { radiance where it falls } \\
\text { between } 2 \text { thresholds. } \\
\text { Glint and aerosol are } \\
\text { estimated together. }\end{array}$ & $\begin{array}{l}\text { Cox and Munk model of } \\
\text { the sea surface; neglects } \\
\text { effects of wind direction, } \\
\text { multiple scattering. }\end{array}$ & Ocean color & $\begin{array}{l}\text { Together with } \\
\text { aerosol } \\
\text { scattering, } \\
\text { Rayleigh } \\
\text { scattering } \\
\text { separately }\end{array}$ \\
\hline Open ocean & $\begin{array}{l}\text { Montagner, } \\
\text { Billat \& } \\
\text { Belanger [7] }\end{array}$ & MERIS & $\begin{array}{l}\text { Glint is predicted from } \\
\text { wind speed and direction } \\
\text { (ECMWF data) and } \\
\text { subtracted from } \\
\text { reflectance where it falls } \\
\text { between } 2 \text { thresholds. }\end{array}$ & $\begin{array}{l}\text { Cox and Munk model of } \\
\text { the sea surface; neglects } \\
\text { effects of multiple } \\
\text { scattering, aerosol. }\end{array}$ & Ocean color & Before \\
\hline Open ocean & $\begin{array}{l}\text { Fukushima } \\
\text { et al. }[40]\end{array}$ & GLI & $\begin{array}{l}\text { Similar to SeaWiFS, but } \\
\text { with wind speed from } \\
\text { SeaWinds microwave } \\
\text { scatterometer on the same } \\
\text { satellite (ADEOS-II). }\end{array}$ & $\begin{array}{l}\text { Cox and Munk model of } \\
\text { the sea surface; neglects } \\
\text { effects of wind direction, } \\
\text { multiple scattering. }\end{array}$ & Ocean color & $\begin{array}{l}\text { Together with } \\
\text { aerosol } \\
\text { scattering, } \\
\text { Rayleigh } \\
\text { scattering } \\
\text { separately }\end{array}$ \\
\hline Open ocean & $\begin{array}{l}\text { Ottaviani } \\
\text { et al. }[41]\end{array}$ & SeaWiFS & $\begin{array}{l}\text { Uses a solution of the full } \\
\text { radiative transfer equation } \\
\text { to include the effect of } \\
\text { multiple scattering, } \\
\text { multiple reflection and } \\
\text { shadowing. }\end{array}$ & $\begin{array}{l}\text { Cox and Munk model of } \\
\text { the sea surface; neglects } \\
\text { effects of wind direction. }\end{array}$ & Ocean color & Together \\
\hline $\begin{array}{l}\text { Open ocean } \\
\text {-but a } \\
\text { different } \\
\text { approach }\end{array}$ & $\begin{array}{l}\text { Steinmetz, } \\
\text { Deschamps } \\
\text { \& Ramon [3] }\end{array}$ & MERIS & $\begin{array}{l}\text { Aerosol and glint } \\
\text { correction are made } \\
\text { together by matching } \\
\text { reflectance using a neural } \\
\text { network or iterative mean } \\
\text { square minimization } \\
\text { method. }\end{array}$ & $\begin{array}{l}\text { Polynomial model of } \\
\text { glint and atmospheric } \\
\text { factors. }\end{array}$ & Ocean color & $\begin{array}{l}\text { Together with } \\
\text { aerosol } \\
\text { scattering, } \\
\text { Rayleigh } \\
\text { scattering } \\
\text { separately }\end{array}$ \\
\hline $\begin{array}{l}\text { Open ocean } \\
\text {-another } \\
\text { alternative }\end{array}$ & $\begin{array}{l}\text { Doerffer } \\
\text { et al. }[42]\end{array}$ & MERIS & $\begin{array}{l}\text { A neural network is used } \\
\text { to correct both glint and } \\
\text { atmospheric effects. } \\
\text { Wind speed is not used. }\end{array}$ & $\begin{array}{l}\text { No explicit assumptions, } \\
\text { but the neural network is } \\
\text { trained using data from } \\
\text { radiative transfer } \\
\text { simulations, which will } \\
\text { have built-in } \\
\text { assumptions. }\end{array}$ & Ocean color & Together \\
\hline $\begin{array}{l}\text { Shallow } \\
\text { waters }\end{array}$ & $\begin{array}{l}\text { Hochberg, } \\
\text { Andrefouet } \\
\text { \& Tyler [2] }\end{array}$ & IKONOS & $\begin{array}{l}\text { NIR is used to find the } \\
\text { spatial variation of glint } \\
\text { across the image, by } \\
\text { scaling depending on the } \\
\text { brightest and darkest } \\
\text { points (NIR). }\end{array}$ & $\begin{array}{l}\text { Refractive index is } \\
\text { independent of } \\
\text { wavelength; low NIR } \\
\text { water-leaving radiance. }\end{array}$ & $\begin{array}{l}\text { Sub-surface } \\
\text { imaging } \\
\text { (e.g., reef, } \\
\text { estuary) }\end{array}$ & After \\
\hline
\end{tabular}


Table 4. Cont.

\begin{tabular}{|c|c|c|c|c|c|c|}
\hline $\begin{array}{l}\text { Method } \\
\text { type }\end{array}$ & $\begin{array}{l}\text { Authors and } \\
\text { ref. }\end{array}$ & $\begin{array}{l}\text { Demonstration } \\
\text { instrument }\end{array}$ & Outline of method & Assumptions & $\begin{array}{l}\text { Examples of } \\
\text { use }\end{array}$ & $\begin{array}{l}\text { Before/after } \\
\text { atmospheric } \\
\text { correction }\end{array}$ \\
\hline $\begin{array}{l}\text { Shallow } \\
\text { waters }\end{array}$ & $\begin{array}{l}\text { Hedley, } \\
\text { Harborne and } \\
\text { Mumby [10] }\end{array}$ & IKONOS & $\begin{array}{l}\text { Refined the method of } \\
\text { Hochberg et al. [2] using a } \\
\text { group of pixels that have } \\
\text { similar underlying brightness } \\
\text { (e.g., deep water) rather than } \\
\text { just two. }\end{array}$ & $\begin{array}{l}\text { Refractive index is } \\
\text { independent of } \\
\text { wavelength; low NIR } \\
\text { water-leaving radiance. }\end{array}$ & $\begin{array}{l}\text { Sub-surface } \\
\text { imaging } \\
\text { (e.g., reef, } \\
\text { estuary) }\end{array}$ & After \\
\hline $\begin{array}{l}\text { Shallow } \\
\text { waters }\end{array}$ & $\begin{array}{l}\text { Lyzenga, } \\
\text { Malinas and } \\
\text { Tanis [9] }\end{array}$ & IKONOS & $\begin{array}{l}\text { Sun glint correction factor for } \\
\text { a given band is based on } \\
\text { covariance of radiance in that } \\
\text { band and in NIR for a deep } \\
\text { water area. }\end{array}$ & $\begin{array}{l}\text { No upwelling radiance } \\
\text { for deep water. }\end{array}$ & Bathymetry & After \\
\hline $\begin{array}{l}\text { Shallow } \\
\text { waters }\end{array}$ & Philpot [38] & AVIRIS & $\begin{array}{l}\text { Use of info from a glint- } \\
\text { contaminated and non- } \\
\text { contaminated pixel pair to } \\
\text { calculate glint radiance. This } \\
\text { is then extended to nearby } \\
\text { pixels using NIR. }\end{array}$ & $\begin{array}{l}\text { Uniform atmosphere } \\
\text { across the region where } \\
\text { glint correction is } \\
\text { applied } \\
\text { No water-leaving } \\
\text { radiance for NIR. No } \\
\text { glint in dark pixel. }\end{array}$ & $\begin{array}{l}\text { Bathymetry } \\
\text { and water } \\
\text { properties in } \\
\text { shallow } \\
\text { water }\end{array}$ & Before \\
\hline $\begin{array}{l}\text { Shallow } \\
\text { waters }\end{array}$ & $\begin{array}{l}\text { Goodman, } \\
\text { Lee \& Ustin } \\
{[1]}\end{array}$ & AVIRIS & $\begin{array}{l}\text { At each wavelength an offset } \\
\text { is added, depending on } \\
\text { difference between } \\
\text { reflectance at } 640 \text { and } 750 \\
\mathrm{~nm} \text {. }\end{array}$ & $\begin{array}{l}\text { Method is based on a } \\
\text { radiative transfer } \\
\text { model. }\end{array}$ & $\begin{array}{l}\text { Bathymetry } \\
\text { and water } \\
\text { properties in } \\
\text { shallow } \\
\text { water }\end{array}$ & After \\
\hline $\begin{array}{l}\text { Shallow } \\
\text { waters }\end{array}$ & $\begin{array}{l}\text { Kutser, } \\
\text { Vahtmäe \& } \\
\text { Praks [43] }\end{array}$ & AISA & $\begin{array}{l}\text { The depth of the } 760 \mathrm{~nm} \\
\text { oxygen absorption band is } \\
\text { used to indicate the amount of } \\
\text { glint. }\end{array}$ & $\begin{array}{l}\text { Glint is the only } \\
\text { process affecting the } \\
\text { absorption depth; depth } \\
\text { is proportional to } \\
\text { amount of glint. }\end{array}$ & $\begin{array}{l}\text { Bathymetry } \\
\text { and water } \\
\text { properties in } \\
\text { shallow } \\
\text { water }\end{array}$ & After \\
\hline
\end{tabular}

\section{Correction Methods Based on Statistical Models of the Sea Surface State}

The first class of methods use the statistics of the sea surface, for a given wind vector, to predict how much sunlight will be reflected to each image pixel. The predicted glint can then be subtracted or, if the predicted contamination is too strong, the pixel can be masked. This section first outlines the Cox and Munk model of the sea surface state and then describes how this model has been implemented in the processing schemes for SeaWiFS (through SeaDAS) and MERIS. Some new methods using neural networks are also described briefly.

\subsection{The Cox and Munk Statistical Model of the Sea Surface State}

In classic work from the 1950s, Cox and Munk [4,5,30] developed a wind-speed dependent probability distribution function for the sea surface slope by measuring aerial photographs of reflected sunlight. As discussed in Section 2.2, a PDF of slopes can be used to predict the amount of sun glint (see Equation 12). Their measurements gave a PDF that was approximately Gaussian, and they expressed it as a Gram-Charlier expansion to the $4^{\text {th }}$ term [44]:

$$
\begin{aligned}
p(\xi, \eta)=\frac{1}{2 \pi} & \exp \left(-\frac{1}{2}\left(\xi^{2}+\eta^{2}\right)\right)\left[1+\frac{1}{2} c_{12} \xi\left(1-\eta^{2}\right)+\frac{1}{6} c_{30} \xi\left(3-\xi^{2}\right)\right. \\
& \left.+\frac{1}{24} c_{40}\left(3-6 \xi^{2}+\xi^{4}\right)+\frac{1}{4} c_{22}\left(1-\xi^{2}\right)\left(1-\eta^{2}\right)+\frac{1}{24} c_{04}\left(3-6 \eta^{2}+\eta^{4}\right)\right]
\end{aligned}
$$


where $\xi=Z_{X} / \sigma_{W}$ and $\eta=Z_{y} / \sigma_{c}$ are normalized surface slopes; $\sigma_{W}$ and $\sigma_{c}$ are the root mean square slopes in the downwind $(x)$ and crosswind $(y)$ directions. Note that here axes with $x$ in the downwind direction are chosen, as is common in recent papers, e.g., [45,44]. Some authors, including Cox and Munk's original work, take the $y$-axis as upwind, so the equation appears slightly different. The initial multiplier is sometimes also shown as including $\sigma_{w} \sigma_{c}$ as well as $2 \pi$, but as normalized variables are used this is not necessary.

In Equation 13 the initial "1" in the square bracket gives a Gaussian distribution of slopes, the later terms modify the Gaussian. $c_{12}$ and $c_{30}$ relate to the skewness of the distribution, $c_{40}, c_{22}$ and $c_{04}$ to the peakedness. In Cox and Munk's model the values of these parameters are given by [5]:

$$
c_{12}=0.01-0.0086 U \quad c_{30}=0.04-0.033 U \mathrm{c}_{40}=0.23 \mathrm{c}_{22}=0.12 \mathrm{c}_{04}=0.40
$$

and the mean square slope (mss) has a close to linear relationship with wind speed:

$$
\begin{gathered}
{\sigma_{w}}^{2}=0.00316 U \pm 0.004 \\
{\sigma_{c}}^{2}=0.003+0.00192 U \pm 0.004 \\
\mathrm{mss}=\sigma_{w}{ }^{2}+\sigma_{c}{ }^{2}=0.003+0.00512 U \pm 0.004
\end{gathered}
$$

This model enables the PDF to be calculated for any sun and sensor position, as long as the wind speed and direction are known.

The Cox and Munk model, based on 29 photographs taken over a period of 20 days in one geographical area, has proved remarkably robust. The mean square slopes can be used to calculate the PDF to a Gaussian approximation, and have been the focus of most attention. Wu [46] reanalyzed the data and suggested a slightly different expression for the mean square slope:

$$
\begin{aligned}
& \text { mss }=\left(0.90+1.20 \ln U_{10}\right) \times 10^{-2} \quad \text { for } U_{10}<7 \mathrm{~ms}^{-1} \\
& \text { mss }=\left(-8.40+6.00 \ln U_{10}\right) \times 10^{-2} \quad \text { for } U_{10}>7 \mathrm{~ms}^{-1}
\end{aligned}
$$

where $U_{10}$ is the wind speed at $10 \mathrm{~m}$. Figure 4 shows a comparison of this model with Cox and Munk's data and model.

However, there have been only a few attempts to collect further data until recently (see [47] for some examples). In the last decade several studies have repeated the method of Cox and Munk, but using much larger data sets from satellite-borne radiometers and scatterometers able to gather concurrent radiance and wind data. Ebuchi and Kizu [48] used about 30 million data points gathered over 4 years' observation of subtropical seas. They found that the distribution of slopes was narrower than the Cox and Munk model and the dependence on wind direction was weaker:

$$
\begin{gathered}
{\sigma_{w}}^{2}=0.0053+0.000671 U_{10} \\
{\sigma_{c}}^{2}=0.0048+0.00152 U_{10} \\
\mathrm{mss}={\sigma_{w}}^{2}+{\sigma_{c}}^{2}=0.0101+0.00219 U_{10}
\end{gathered}
$$

There is significant disagreement between this model and that of Cox and Munk in the along-wind direction (Figure 4). The authors suggest that this may be due to the lower spatial resolution of their data, or to the limited set of conditions for the Cox and Munk data set, which were obtained for growing to fully-developed wind waves and did not include swell. 
Figure 4. Mean square slopes of the sea surface plotted against wind speed for the Cox and Munk data and for the models of Cox and Munk [5], Wu [46] (overall mss only), Ebuchi \& Kizu [48] and Breon \& Henriot [49]. (a) overall mean square slope (b) along the wind direction (c) crosswind. All data are for clean surfaces, not slicks. Note that the Cox and Munk wind measurements were actually made at $12.5 \mathrm{~m}$ rather than $10 \mathrm{~m}$, and that Cox and Munk's data point at $U=0.89 \mathrm{~ms}^{-1}$ is omitted because they considered it to be unreliable.

(a)

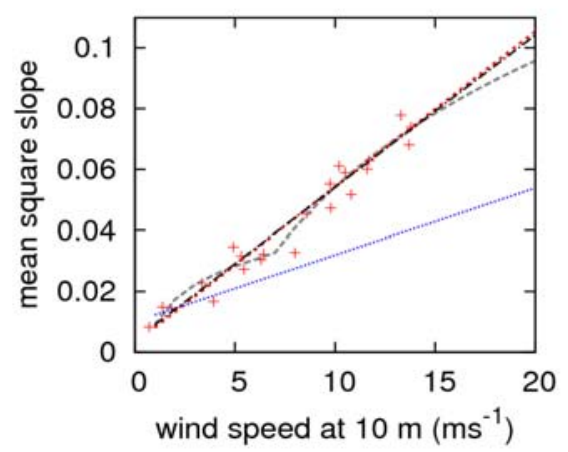

Cox and Munk (1954), data
Cox and Munk (1954), model Wu (1990) (b)

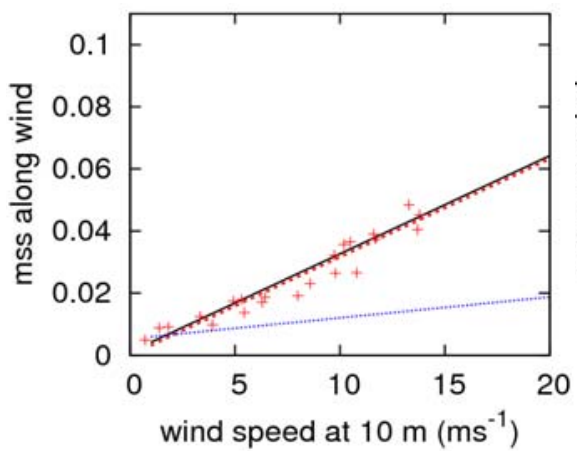

(c)

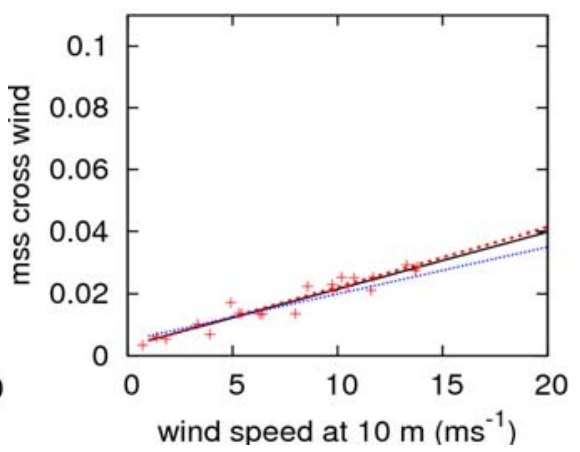

Bréon and Henriot [49] analyzed a set of nine million reflectance measurements from 24,000 glint-affected observations by the POLDER instrument, with concurrent wind data from the NASA Scatterometer on the same satellite. The images were taken over an eight month period (September 1999-June 1997) and have global coverage. Their analysis backs up the Gram-Charlier expansion with a linear relationship between the wind speed and the mean square slope (Figure 4). The parameters are slightly different and the estimate of uncertainty is reduced:

$$
\begin{gathered}
\sigma_{w}{ }^{2}=0.001+0.00316 U_{10} \pm 0.00005 \\
{\sigma_{c}}^{2}=0.003+0.00185 U_{10} \pm 0.00005
\end{gathered}
$$

The skewness shows a different behavior, saturating at high wind speeds, and the peakedness is larger than the Cox and Munk model:

$$
\begin{aligned}
& c_{12}=0.0009 U_{10}^{2} \pm 0.01 \quad c_{30}=0.45\left(1+e^{7-U_{10}}\right)^{-1} \pm 0.01 \\
& c_{40}=0.3 \pm 0.05 \quad c_{22}=0.4 \pm 0.1 \quad c_{04}=0.12 \pm 0.03
\end{aligned}
$$

The accuracy of the Cox and Munk model is also supported by the study of Fox et al. [50], who compared estimates of wind speed made from satellite measurements of glint patterns with data from buoys. Fukushima et al. [47] carried out a similar study using radiance data from GLI images (Table 1) and concurrent wind data from the SeaWinds scatterometer on the same satellite - this derives wind speed by an empirical algorithm rather than using the Cox and Munk model. They found good agreement with Cox and Munk for moderate wind speeds, but the model of Ebuchi and Kizu was a better fit in calm conditions. This difference in response at lower wind speed is reminiscent of Wu's reanalysis of the Cox and Munk data (Equation 18). The study of Gatebe et al. [51], using data from 
airborne instruments for coastal and deep waters in the western Atlantic Ocean, found that the Cox and Munk model fitted their data well for most conditions, but underestimated the maximum glint for wind speeds below $3 \mathrm{~m} / \mathrm{s}$.

In summary, recent studies have suggested some minor modifications but they have left unchanged the main features of the Cox and Munk model: the Gaussian distribution of slopes and the linear dependence of mean square slope on wind speed.

This model of sea surface slope is currently used to predict and, where possible, correct sun glint contamination in data from a number of ocean color instruments (see Table 1 for instrument information). The correction scheme developed for SeaWiFS is outlined in the next section, and variations on this are discussed in Section 4.3.

\subsection{The SeaWiFS Correction Method}

Wang and Bailey [4] studied the effect of sun glint on SeaWiFS images. Prior to 2000, SeaWiFS relied on tilting to avoid sun glint, and masking of glint areas that remained by using the Cox and Munk model to predict which pixels would be contaminated. Wang and Bailey proposed a correction method in which the sun glint radiance and aerosol optical thickness are estimated together. This algorithm is now used routinely for SeaWiFS and a number of other sensors [31], and it is available to users as part of the SeaDAS package [52].

In the SeaWiFS method the top-of-atmosphere radiance measured at the sensor is analyzed according to its source:

$$
L_{\text {sensor }}(\lambda)=L_{\text {Rayleigh }}(\lambda)+L_{\text {aerosol }}(\lambda)+L_{\mathrm{ra}}(\lambda)+T(\lambda) L_{\text {glint }}(\lambda)+t(\lambda) L_{\text {whitecap }}(\lambda)+t(\lambda) L_{\text {water }}(\lambda)
$$

Here $L_{\text {Rayleigh }}(\lambda)$ is the radiance due to Rayleigh scattering, $L_{\text {aerosol }}(\lambda)$ to aerosol and $L_{\mathrm{ra}}(\lambda)$ to Rayleigh-aerosol interactions - together these 3 terms make up most of the $L_{\text {atm }}$ term of Equation 1. $T(\lambda)$ and $t(\lambda)$ are the direct and diffuse transmittances through the atmosphere - diffuse transmittance includes both direct transmission and light scattered into the path to the sensor, an example of a more complex path omitted from Figure 2. It is assumed that sun glint, which is highly directional, results from directly transmitted solar radiance, whereas the diffuse transmittance is more appropriate for white cap and water-leaving radiance. The other symbols are as listed in Table 2. The aim of the sun glint correction is to subtract the glint radiance $T(\lambda) L_{\text {glint }}$ from the measured value $L_{\text {sensor }}$, leaving a corrected radiance that can then be processed further to remove other terms and leave $L_{\text {water }}$.

The SeaWiFS scheme uses radiances normalized to the values they would have if there was no atmosphere and the solar irradiance was 1 . For example the normalized sun glint radiance is defined by:

$$
L_{\mathrm{GN}}\left(\lambda, \theta_{s}, \varphi_{s}, \theta_{v}, \varphi_{v}, \boldsymbol{W}\right)=\frac{L_{\mathrm{glint}}(\lambda)}{F_{\mathrm{o}}(\lambda) T_{\mathrm{o}}(\lambda)}
$$

where $F_{o}(\lambda)$ is the extraterrestrial solar irradiance and the $T_{o}(\lambda)$ the atmospheric direct transmittance from the top of atmosphere to the surface, so $T_{o}(\lambda)$ would be 1 if there were no atmosphere.

The normalized glint radiance can be calculated by combining Equations 12 and 26 and using $E=F_{o}(\lambda) T_{o}(\lambda) \cos \theta_{s}$ for the irradiance at the surface. As shown in Sections 2.2 and 4.1 (Equations 9, 10 
and 13-16), the probability depends on the solar and viewing geometry described by $\theta_{s,} \varphi_{s,} \theta_{V}, \varphi_{V}$ (Table 2) and on the wind vector $\boldsymbol{W}$.

$$
L_{\mathrm{GN}}\left(\lambda, \theta_{s}, \varphi_{s}, \theta_{v}, \varphi_{v}, \boldsymbol{W}\right)=\frac{\rho(\omega, \lambda) p\left(\theta_{s}, \varphi_{s}, \theta_{v}, \varphi_{v}, \boldsymbol{W}\right)}{4 \cos ^{4} \beta \cos \theta_{v} \cos \theta_{s}}
$$

$\rho(\omega, \lambda)$ is the Fresnel reflectance, approximated as varying with angle but not wavelength:

$$
\rho(\omega)=\frac{1}{2}\left[\left(\frac{\sin \left(\omega-\omega^{\prime}\right)}{\sin \left(\omega+\omega^{\prime}\right)}\right)^{2}+\left(\frac{\tan \left(\omega-\omega^{\prime}\right)}{\tan \left(\omega+\omega^{\prime}\right)}\right)^{2}\right]
$$

where $\omega$ is the angle of incidence and $\omega^{\prime}$ is the angle of refraction, i.e., $\sin \omega^{\prime}=\sin \omega / n$. The refractive index $n$ is taken as 4/3 regardless of wavelength. In fact $n$ varies with wavelength from 1.34 to 1.35 for sea water, see section 2.1, giving $\rho$ from 0.021 to 0.023 at $20^{\circ}$ incidence and 0.060 to 0.064 at $60^{\circ}$ - the variation with angle is much greater than that with wavelength, justifying the approximation.

The probability distribution function $p\left(\theta_{s}, \varphi_{s}, \theta_{V}, \varphi_{V}, W\right)$ is approximated by a Gaussian distribution, i.e., all but the first term in Equation 13 are ignored. The wind direction is also neglected, with an approximation to the mean square slopes $\sigma_{w}$ and $\sigma_{c}$ used to simplify the calculations:

$$
\sigma_{w} \approx \sigma_{c} \approx \mathrm{mss}=0.0493 \mathrm{~W}
$$

$L_{\mathrm{GN}}$ is calculated for each pixel using Equation 27 and pixels are masked where its value is above a certain threshold $\left(0.005 \mathrm{sr}^{-1}\right.$ in SeaWiFS processing up to the year 2000). It can also be used to calculate the glint correction:

$$
T(\lambda) L_{g}(\lambda)=F_{o}(\lambda) T(\lambda) T_{o}(\lambda) L_{\mathrm{GN}}\left(\lambda, \theta_{s}, \varphi_{s}, \theta_{v}, \varphi_{v}, \boldsymbol{W}\right)
$$

Extraterrestrial solar irradiance $F_{o}(\lambda)$ can be calculated for any given date, time and location. The atmospheric transmittance from the sun to the surface and then from the surface to the sensor is given by:

$$
T(\lambda) T_{o}(\lambda)=\exp \left\{-\left[\tau_{\text {aerosol }}(\lambda)+\tau_{\text {Rayleigh }}(\lambda)\right]\left(1 / \cos \theta_{s}+1 / \cos \theta_{v}\right)\right\}
$$

where $\tau_{\text {aerosol }}(\lambda)$ and $\tau_{\text {Rayleigh }}(\lambda)$ are the aerosol and Rayleigh optical thicknesses. Although $\tau_{\text {Rayleigh }}$ can be calculated, the aerosol type and concentration are not known so a process of successive calculation of $T T_{o}$, $L_{\text {aerosol, }}$, and $\tau_{\text {aerosol }}$ is used to derive both the glint correction and the aerosol optical thickness, starting from an average value of $\tau_{\text {aerosol. }}$

Wang and Bailey [6] compared SeaWiFS water-leaving radiance, normalized to remove the effect of the atmosphere, to in situ data collected by the Marine Optical Buoy (MOBY) system. The ratio of SeaWiFS to in situ radiance ranged, depending on band, from 0.9844 to 1.0293 in areas with uncorrected glint, and from 0.9805 to 1.0094 in the same areas after glint correction. So the overall improvement is small, but in uncorrected glint areas the normalized water-leaving radiance at $555 \mathrm{~nm}$, $\left[L_{m}(555)\right]_{\mathrm{N}}$, was overestimated; this band is used in the bio-optical algorithm to retrieve ocean chlorophyll concentration, so reducing the error leads to more accurate retrieval. In a case study by the same authors the modal value of the chlorophyll concentration in a glint-contaminated area was reduced from 0.108 to $0.096 \mathrm{mg} / \mathrm{m}^{3}$ by applying the glint correction. The modal aerosol optical thickness $\tau_{a}(865)$ was also reduced, from 0.11 to 0.09 , and the values of $\left[L_{m}(555)\right]_{\mathrm{N}}$ and aerosol optical thickness were a better match to nearby uncontaminated pixels after glint correction. The results of an 
analysis of eight-day global data support the results of the case study, and show that the glint correction can be used with normalized glint radiances as high as 0.01 without loss of accuracy. Thus more data can be retrieved in the area around the sub-solar point where glint is highest.

The correction method described in this section is implemented in the SeaDAS package, available at [52]. SeaDAS can be used to process data from MODIS, OCTS and CZCS as well as SeaWiFS. The correction scheme for MODIS, which is sensitive to polarization, uses different Fresnel reflectances for light polarized parallel and perpendicular to the boundary [8]. The sea surface slope PDF used for MODIS glint prediction was changed to that of Ebuchi \& Kizu [48] in July 2003, but NASA reverted to Cox and Munk in November 2003 [53]. A note on the Ocean Color Forum briefly mentions that the effect was found to be minimal [54]-in spite of the apparent difference from the Cox and Munk model (Figure 4).

\subsection{Other Methods Using Sea Surface Slope Statistics: MERIS and GLI}

The MERIS sun glint correction scheme [7] also uses the Cox and Munk probability distribution to predict and, where possible, correct glint contamination. However, the correction is carried out at a different stage of data processing from the SeaDAS method, and independently of the aerosol retrieval.

In the MERIS data processing scheme level 1 involves quality checks on the received radiances, geolocation, initial classification of pixels as land, ocean or bright and calculation of top of atmosphere radiances for each band. An initial estimate of glint is made and used to flag pixels at risk of contamination - this assumes specular reflection from a flat sea surface, with no account taken of sea state, so can only be approximate [55].

Level 2 processing involves the derivation of geophysical measurements such as surface reflectance and chlorophyll concentration from the top-of-atmosphere radiances [56]. The first steps are calculation of reflectance and the identification of pixels as cloud, land or water. Then all water pixels are tested for glint by comparing the reflectance to the predicted glint reflectance:

$$
R_{\text {glint }}=\frac{\pi L_{\text {glint }}}{E \cos \theta_{s}}=\frac{\rho(\omega, \lambda) p(\xi, \eta)}{4 \cos ^{4} \beta \cos \theta_{v} \cos \theta_{s}}
$$

$p(\xi, \eta)$ is the Cox and Munk PDF, as given by Equations 13-16. $\rho(\omega, \lambda)$, the Fresnel reflection coefficient, is approximated as a constant, 0.02-this is considered accurate enough for angles of incidence up to $50^{\circ}$. MERIS views out to $34^{\circ}$ from nadir, so $50^{\circ}$ incidence would mean solar zenith angles greater than $66^{\circ}$ and surface slopes greater than $16^{\circ}$-in the Cox and Munk PDF this slope is more than 4 standard deviations from the mean, even at a surface wind speed of $20 \mathrm{~m} / \mathrm{s}$, so has low probability. In fact there will be some inaccuracy at lower angles: for sea water $\rho(\omega)$ is about $0.021-0.023$ at $20^{\circ}, 0.025-0.027$ at $40^{\circ}$ and $0.034-0.037$ at $50^{\circ}$, depending on wavelength. Wind speed and direction to calculate the PDF are taken from ECMWF global models.

The glint reflectance is then converted to a top of atmosphere reflectance using an estimate of atmospheric transmittance that includes Rayleigh scattering and ozone but not aerosols. For medium glint reflectance the pixel is corrected by subtracting the glint. Low glint values are not adjusted, to avoid over-correction given the uncertainty in the wind data and in the Cox and Munk model-the threshold is set at the lowest level where glint is found to affect the atmospheric correction. High levels, where the glint reflectance at $865 \mathrm{~nm}$ is more than $80 \%$ of the observed reflectance, are flagged 
and not processed further - for these values glint is significantly affecting the aerosol retrieval and correction is not possible (Figure 5). Atmospheric correction, including aerosol, is done at a later stage of level 2 processing.

Figure 5. Illustration of MERIS glint correction and masking, in an image of part of the South Pacific. (a) Level 1 image, with glint apparent on the right side. (b) Level 2 image, masked to show the areas of moderate glint (light pink) and high glint (dark pink). (c) Level 2 image showing the calculated levels of chlorophyll 1 - no retrieval can be made in the high glint region, or cloudy areas, but retrieval is considered sufficiently accurate in the moderate glint region where glint has been corrected.

(a)

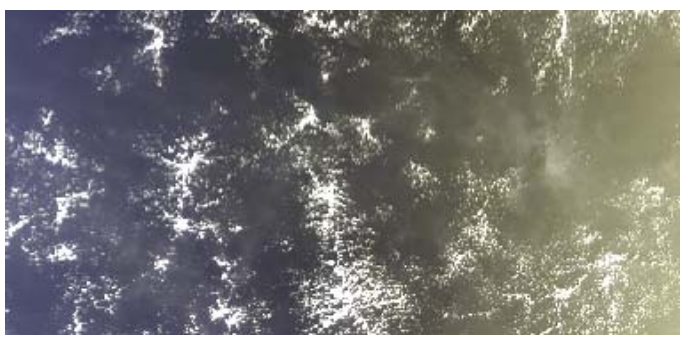

(b)

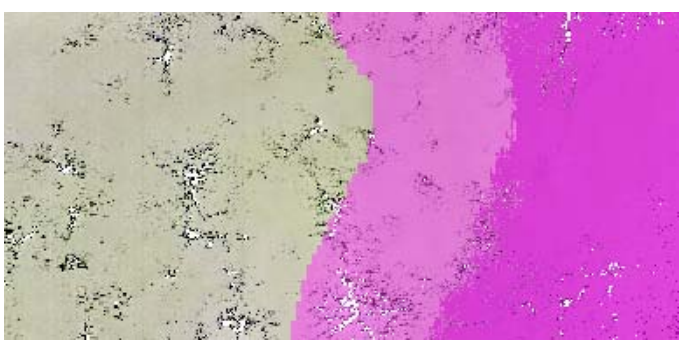

(c)

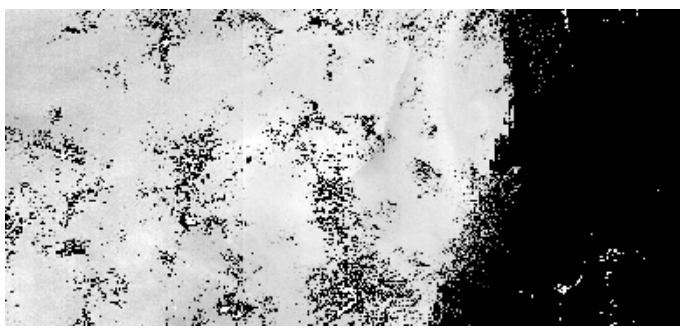

Fukushima et al. [40] investigated the effect of glint correction on data from the Global Imager sensor, a multispectral sensor mounted on the ADEOS-II satellite (see Table 1). The original data processing scheme for this instrument was based on the early SeaWiFS model, including prediction and masking of glint. The second version brought in several changes:

- a new aerosol correction method, which allows for absorption as well as scattering;

- sun glint correction by calculating a glint reflectance and subtracting it from the received value; it is not clear whether this is done before or after the atmospheric correction;

- wind data taken from the SeaWinds microwave scatterometer mounted on the same satellite as GLI, instead of from the Japanese Meteorological Agency.

Fukushima et al. compared their corrected data with data from ship-borne radiometers. They found that the tendency to over-predict aerosol optical thickness in glint regions was significantly reduced, even when the glint reflectance was as high as 0.05 , compared to a masking threshold of 0.005 in the original scheme. They also found some improvement in the value of the aerosol optical thickness and 
chlorophyll retrieval. However, it is not possible to assess the contribution of glint correction to this as it was not tested independently of the new aerosol model.

\subsection{Limitations of the SeaWiFS and MERIS Schemes}

Although methods based on the Cox and Munk model are used with most of the ocean color instruments now in operation they do have limitations. The wind data may not have sufficient resolution to capture the effects of local winds, and the Cox and Munk model does not include the effects of atmospheric stability, wind age or swell [57-59] — though the global coverage of the study by Bréon and Henriot [49] gives some confidence in the use of the model for a wide variety of sea states.

As noted in Section 2.1, aerosol values are particularly hard to separate from the glint signal. Steinmetz et al. [3] comment that MERIS atmospheric techniques fail when the glint reflectance rises above 0.005 . Although the SeaWiFS method does attempt to retrieve glint and aerosol together it does not allow for multiple scattering in the atmosphere. None of the methods allow for effects of multiple reflection or shadowing by large waves at the water surface.

Ottaviani et al. [41] addressed the issues of multiple scattering in the atmosphere, multiple reflection and wave shadowing by using a more detailed atmospheric radiative transfer model. They found that ignoring the possibility of atmospheric multiple scattering gave errors of $10 \%-90 \%$ in the estimate of both Rayleigh and aerosol scattering. The errors were largest at the edge of the glint area, which is where the sun glint correction is applied. There is a larger effect when the aerosol load is higher, i.e., when there is more scattering, and the effect also depends on size of aerosol and azimuth angle, with a weak dependence on wind speed. They recommend developing look-up tables, based on this improved model, to get better estimates of glint-corrected radiance. They also looked at the effect of multiple reflection at the water surface and wave shadowing; they found that these could be significant at higher wind speeds for solar and sensor zenith angles over $60^{\circ}$. These results are in line with a similar modeling study done 15 years earlier by Gordon and Wang [32], who concluded that multiple scattering and polarization may be significant, once larger factors like aerosol have been adequately modeled.

\subsection{New Methods Based on Neural Networks}

Other researchers are testing the ability of neural networks to carry out atmospheric and glint correction together without making any assumptions about the sea surface state. Two examples were presented at the $2^{\text {nd }}$ European Space Agency MERIS-(A)ATSR workshop in September 2008. Steinmetz, Deschamps and Ramon [3] have developed an algorithm called POLYMER, in which the reflectance is first corrected for atmospheric absorption and Rayleigh scattering. Then the corrected reflectance is expressed in terms of a polynomial function of wavelength and the water-leaving reflectance.

$$
R(\lambda)=c_{0}+c_{1} \lambda^{-1}+c_{2} \lambda^{-4}+T(\lambda) R_{\text {water }}(\lambda)
$$

Here the first term on the right hand side includes sun glint, clouds, foam and coarse aerosols; the second represents fine aerosols and the third covers couplings between these processes. The fourth, water-leaving reflectance, term is a function of the chlorophyll concentration and the suspended matter 
backscattering coefficient using existing bio-optical models. The five unknowns are evaluated using a neural network or iterative mean square minimization method. In a 3-day global composite image the uncontaminated image area produced by POLYMER is about twice that of the current MERIS method. Its accuracy in retrieving chlorophyll concentration is comparable to the MERIS system, though slightly lower for high concentrations.

At the same workshop, Doerffer et al. [42] presented a neural-network based atmospheric and glint correction processor. This takes as its input 12 MERIS top-of-atmosphere reflectances together with solar and viewing angles and is trained using a data set obtained from radiative transfer simulations. Comparison with MOBY buoy data shows agreement at least as good as the existing MERIS correction scheme, and data retrieval is possible at higher glint levels. The authors suggest there will be further improvement if short wave and thermal infrared bands are used as well as visible and near infrared (see also [60]). In the case of MERIS, this information can be obtained from the AATSR instrument on the same satellite.

\section{Methods for Shallow Water, High Resolution Images}

\subsection{Theoretical Background}

The techniques discussed in Section 4 rely on being able to make a prediction of glint based on a probability distribution of sea surface slopes. This is reasonable at the 100-1,000 m scale of ocean color sensor pixels, but may be less accurate for images at resolutions of 1-10 $\mathrm{m}$, where the pixel size cannot be assumed to be much larger than the features of the water surface and the statistical assumptions about a surface composed of many reflecting facets may not hold [61]. This section discusses published methods for correcting glint in high spatial resolution images. These exploit the high absorption of water at NIR wavelengths and the consequence that the water-leaving radiance $L_{\text {water }}$ for these bands can be assumed negligible. It follows that all the NIR radiance reaching the sensor must have come from atmospheric scattering of the incident solar radiation or from surface reflection. If atmospheric correction has already been applied then the NIR signal must be entirely due to sun glint. Since the Fresnel reflectance of water is only weakly dependent on wavelength (see Section 4.2) the strengths of the glint signal at visible and NIR wavelengths will vary in the same way, so the NIR signal can be used to indicate the amount of glint at visible wavelengths.

The first published methods corrected the data pixel-by-pixel, subtracting a wavelength-independent offset from each band to bring the NIR radiance close to zero [36,62,63]. Later methods have allowed for some non-zero NIR water-leaving radiance; this is possible if the water is not deep and clear-the sea bed, sediment or vegetation can scatter NIR radiance back through the water surface. Hochberg et al. [2], following Mustard et al. [36], scale the size of spatial variation in the NIR by using the brightest and darkest water pixels in the image - their method brings the NIR signal at the darkest pixel to zero, but allows non-zero NIR in other pixels. Philpot [38] takes a similar approach using AVIRIS data. However, this approach uses several bright and dark pixel-pairs, in different parts of the image, to allow for possible atmospheric variation. The use of brightest and darkest pixels to establish the relationship between NIR and visible wavelengths makes these methods vulnerable to errors. Automated extraction of the brightest pixel means it could come from a cloud, land, white cap 
or a small surface object such as a boat unless all non-water areas have been thoroughly masked beforehand. Other methods derive correction information from regions of the scene, rather than individual pixels $[9,10]$. However all the methods have fundamental similarities, and in many cases mathematically amount to almost the same algorithm. This is demonstrated below by a comparison of the methods of Hedley et al. [10], Lyzenga et al. [9] and Goodman et al. [1], and example applications.

Note that all the methods are described in terms of radiance, but can equally well be applied to data expressed as reflectance or digital numbers.

\subsection{The Method of Hedley et al. [10]; Figures 7(b), 8(b)}

In this approach one or more regions of the image are used to scale the relationship between the NIR signal and sun glint. These regions are chosen to include a range of pixel glint levels, but an assumed consistent underlying brightness and very low water-leaving radiance in the NIR (typically deep water areas) are used. For each band a linear regression is made between the NIR radiance and the band radiance, using all the pixels in the selected regions (Figure 6).

Figure 6. Graphical representation of the glint correction method of Hedley et al., based on their Figure 2 [10]. The pixel indicated by the red point is deglinted by reducing its NIR radiance to the minimum found in the sample region, and scaling the visible radiance using the regression slope.

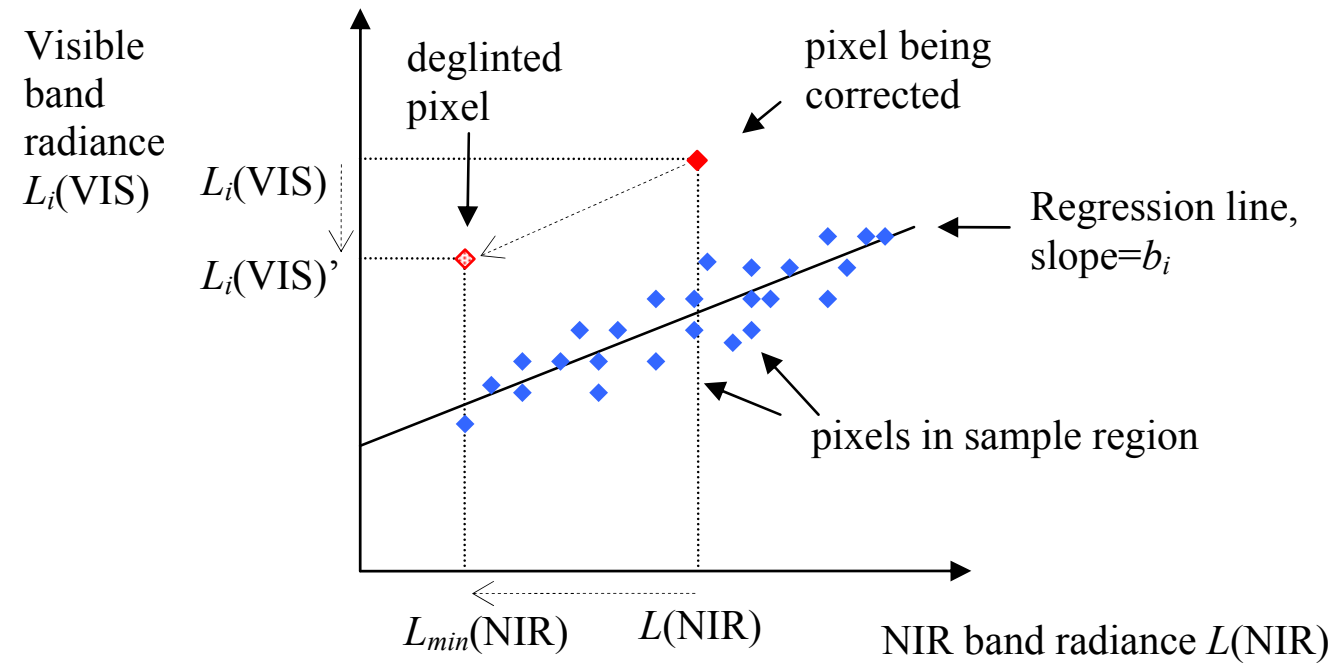

Each pixel is corrected by assuming its glint-free NIR radiance is the same as the minimum value in the sample regions and reducing the visible band accordingly, using the least squares regression slope to give the relationship between the visible and NIR bands (Figure 6). The corrected radiance in the $i^{\text {th }}$ band is then given by:

$$
L_{i}(V I S)^{\prime}=L_{i}(V I S)-b_{i}\left[L(N I R)-L_{\min }(N I R)\right]
$$

where $b_{i}$ is the regression slope. Note that the 2-pixel methods $[2,38]$ use the same approach, but the regression is based on just two points, rather than a best fit across the sample. Using a sample regression minimises the effect of outliers that may be due to surface objects or whitecaps. 
This method is normally applied after atmospheric correction, though if the atmosphere is uniform across the image it can be successfully used first - the effect of aerosols may move the regression line up or down, but will leave the slope constant. However, if atmospheric properties vary from place to place this will change the regression slope, so the effects of glint and aerosol will be confounded. Many aerosol correction methods use NIR techniques similar to the glint correction method, so there is potential for the two methods to affect each other and the order in which the processes are done may affect the final result.

\subsection{The Method of Lyzenga et al. [9]; Figures 7(c), 8(c)}

Instead of a regression this method uses the covariance between each visible band and the NIR to establish the relationship between bands, using chosen region(s) of the image in the same way as Hedley et al.

$$
\operatorname{Cov}(i, j)=\frac{1}{N} \sum_{n=1}^{N} L_{i n} L_{j n}-\frac{1}{N} \sum_{n=1}^{N} L_{i n} \frac{1}{N} \sum_{n=1}^{N} L_{j n}
$$

where band $i$ is the visible band, $j$ is the NIR band and $N$ is the number of pixels in the region of interest. This then gives the coefficient used to scale the NIR signal to work out the glint:

$$
r_{i j}=\frac{\operatorname{Cov}(i, j)}{\operatorname{Var}(j)}
$$

where $\operatorname{Var}(j)$ is the variance in the NIR band $(=\operatorname{Cov}(j, j))$.

The corrected glint is:

$$
L_{i}(V I S)^{\prime}=L_{i}(V I S)-r_{i j}\left[L_{j}(N I R)-\left\langle L_{j}(N I R)\right\rangle\right]
$$

Here $\left\langle L_{j}(N I R)\right\rangle$ is the mean NIR radiance in the region of interest. Note that because Hedley et al. use a least squares method to calculate the regression slope, $r_{i j}$ (in Equation 37) and $b_{i}$ (in Equation 34) are the same. The two methods are equivalent, except that Hedley et al. use the minimum value of the NIR radiance in the final term, where Lyzenga et al. use the mean value. Another variation, by Joyce [64], uses the modal NIR value.

\subsection{The method of Goodman et al. [1]; Figures 7(d), 8(d)}

This method, based on [63], corrects each pixel independently. The NIR radiance is subtracted from the radiance at each wavelength, but a wavelength-independent offset, $\Delta$, is also added:

$$
\begin{gathered}
L_{i}(\lambda)=L_{i}(\lambda)-L(750)+\Delta \\
\Delta=\mathrm{A}+\mathrm{B}[L(640)-L(750)]
\end{gathered}
$$

$\mathrm{A}$ and $\mathrm{B}$ are constants - the values in Goodman et al.'s paper, using AVIRIS reflectance (rather than radiance) data are $A=0.000019$ and $B=0.1$. These would need to be adjusted for other sensors - it is not clear how A and B were chosen, but an optimization for a case where in situ data is available would enable values to be found. 
This method forces the corrected radiance to approach zero at $750 \mathrm{~nm}$, but the offset allows it to be a little above zero (for example in shallow water).

\subsection{The Method of Kutser et al.}

Kutser, Vahtmäe and Praks [43] suggest a variant on these methods, which uses information in the oxygen absorption band at $760 \mathrm{~nm}$ to assess the size of the glint. They assume that the amount of glint is proportional to the depth of the oxygen absorption feature, $D$ :

$$
D=\frac{R(739)+R(860)}{2}-R(760)
$$

Because 739 and $860 \mathrm{~nm}$ are wavelengths outside the oxygen absorption band, the average of their reflectances gives a measure of the reflectance if no oxygen were present. Where $D$ is zero the pixel can be taken to have no glint. For each pixel, $D$ is normalised by dividing it by the maximum $D$ found in a deep water region - this is the maximum glint value. The spectral variation of glint $G(\lambda)$ is found by subtracting the spectrum at the darkest (i.e, lowest $D$ ) NIR deep-water pixel from the brightest:

$$
G(\lambda)=R_{\text {bright }}(\lambda)-R_{\text {dark }}(\lambda)
$$

Then the product of $G(\lambda)$ and the normalised depth $D_{\text {norm }}$ gives the amount of glint for each band at each pixel. The glint can then be subtracted from the reflectance to give the corrected water-leaving radiance $R_{w}$ :

$$
\begin{gathered}
D_{\text {norm }}(x, y)=\frac{D(x, y)}{D_{\max }} \\
R_{w}(x, y ; \lambda)=R(x, y ; \lambda)-G(\lambda) D_{\text {norm }}(x, y)
\end{gathered}
$$

( $D$ may be negative due to noise or a below-water signal, these values are set to zero.)

This method requires high spectral resolution and the ability to collect data very close to $760 \mathrm{~nm}$.

\subsection{Comments on the Methods}

Figures 7 and 8 illustrate some of the effects of these correction methods, on images with crosstrack glint and wave-induced glint respectively. It can be seen that most of the techniques have some success, both on the visual appearance and on the radiance values - in the CASI images (Figure 7) the corrected radiances are uniform across the image, and in the IKONOS images (Figure 8) the peaks caused by glint from the water waves on the right hand side of the images are smoothed out. The exception is the Kutser method, where the closest wavelengths available (706, 781 and $872 \mathrm{~nm}$ ) only approximately matched those suggested $(739,760$ and $860 \mathrm{~nm})$ and the $760 \mathrm{~nm}$ oxygen absorption band was not resolved. The method could not be used at all on the IKONOS data, which has only one NIR band. However, the results presented in [43] suggest that this approach has advantages over other methods in cases where the water-leaving signal is strong, e.g., where vegetation is close to the water surface or the water is less than $2 \mathrm{~m}$ deep. 
Figure 7. CASI images of Plymouth Sound, UK, showing the effects of different glint correction tools. (a) image with no glint correction, showing regions used in correction and analysis. Image corrected using the method of (b) Hedley et al. (c) Lyzenga et al. (d) Goodman et al. (e) Kutser et al.. In each case (i) is a pseudo-true color representation, (ii) shows four wavebands for pixels along the line shown in (a)(i) and (iii) shows a spectral analysis for pixels at each end of the line (i.e., in the glint and no-glint regions). The wavebands used for the pseudo-true color image are blue 438-447 nm, green 556-566 nm, red $666-677 \mathrm{~nm}$.

(a) (i)

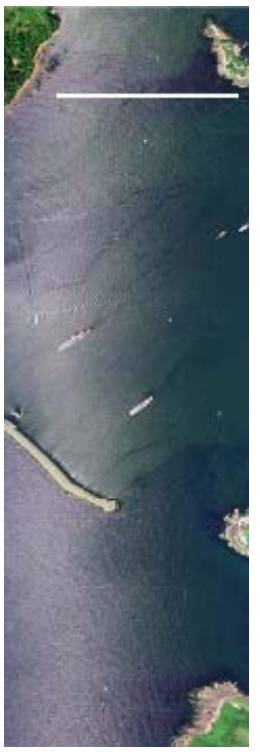

(a) (ii)

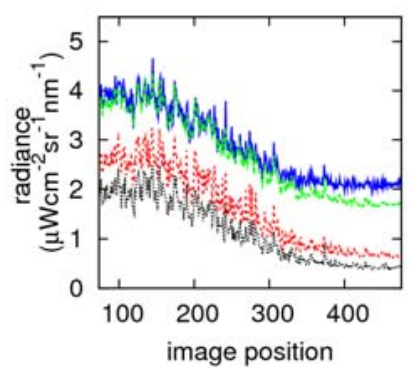

(a) (iii)

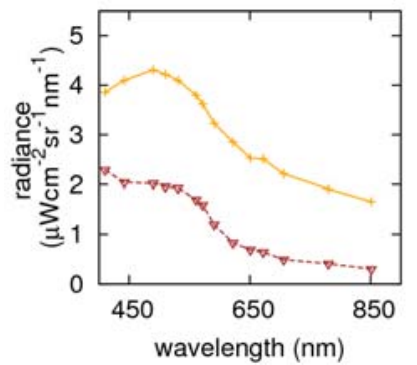

(b) (i)

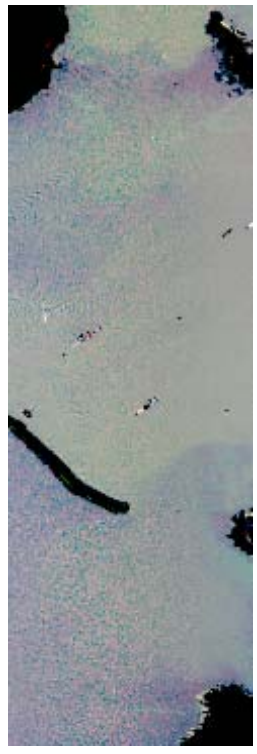

(b) (ii)

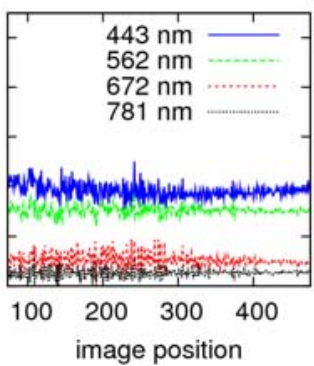

(b) (iii)

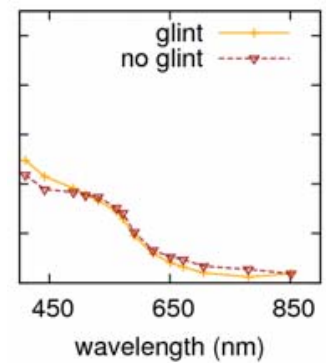

(c) (i)

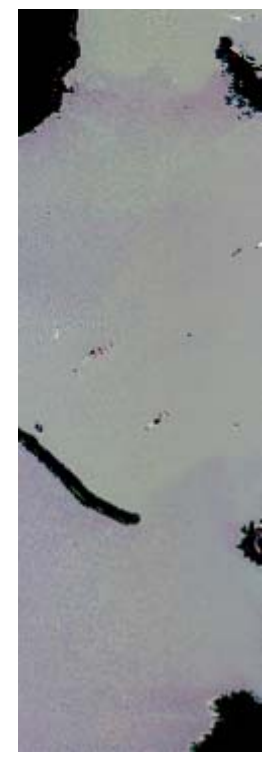

(c) (ii)

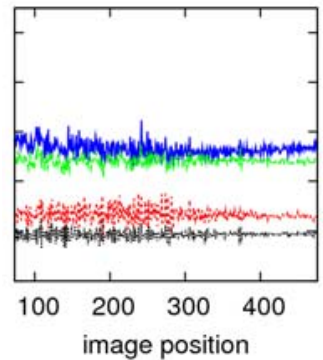

(c) (iii)

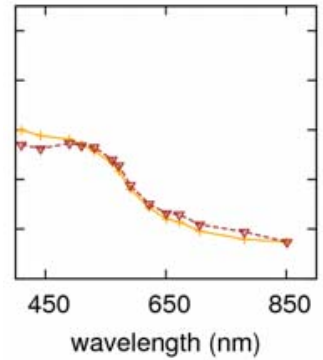

(d) (i)

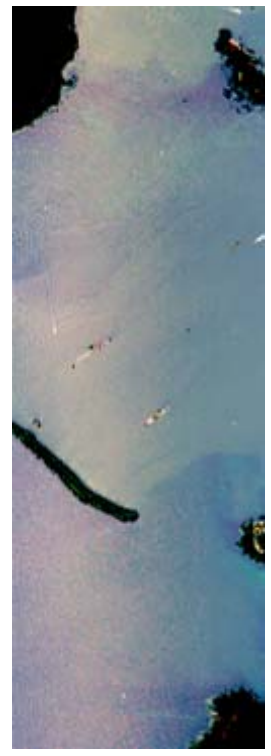

(d) (ii)

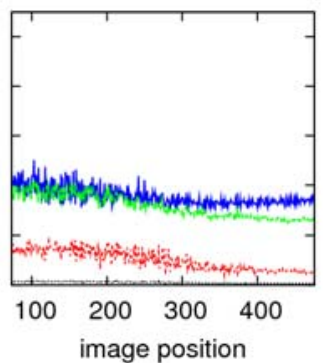

(d) (iii)

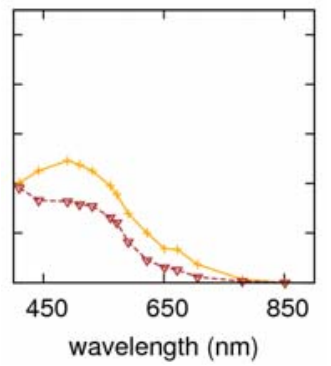

(e) (i)

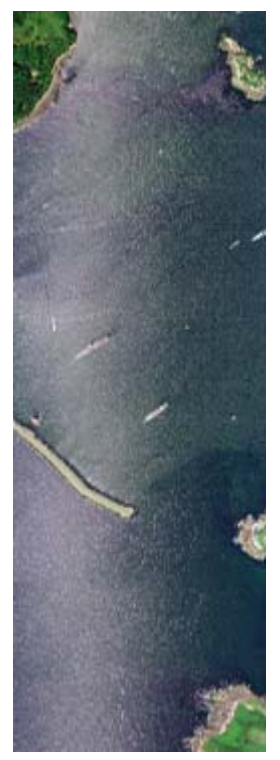

(e) (ii)

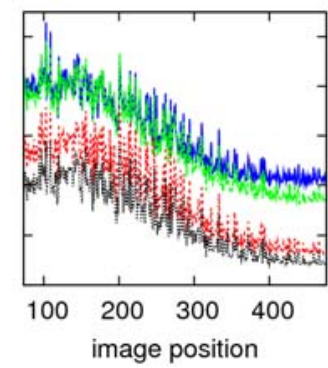

(e) (iii)

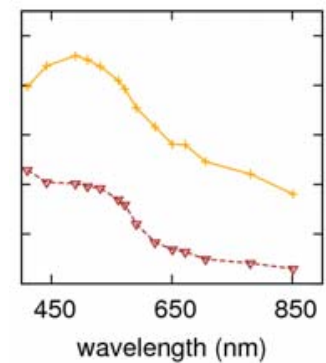


Figure 8. IKONOS images of Glovers' Reef, Belize, showing the effects of different glint correction tools. (a) Image with no glint correction, showing regions used for correction and analysis. Image corrected using the method of (b) Hedley et al. (c) Lyzenga et al. (d) Goodman et al. In each case (i) is a pseudo-true color representation (blue $=445-516 \mathrm{~nm}$, green $=506-595 \mathrm{~nm}$, red $=632-698 \mathrm{~nm}$ ), (ii) shows four wavebands for pixels along the lines shown in (a) (i), (iii) is another pseudo-true color image, less contaminated by glint and with greater magnification, (iv) shows four wavebands for the line in (a) (iii).

(a) (i)

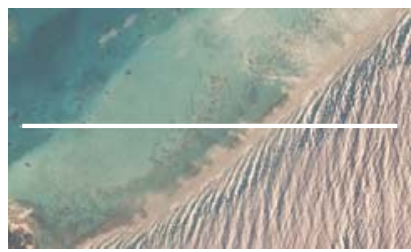

(a) (ii)

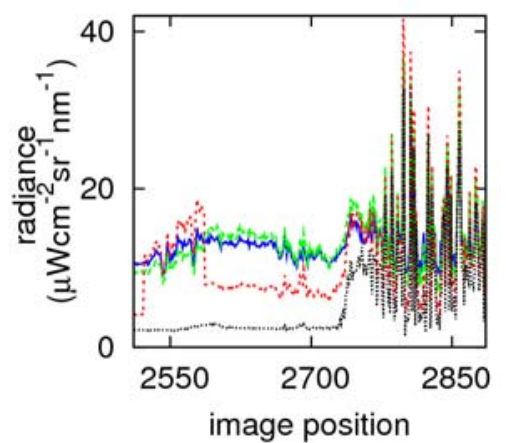

(a) (iii)

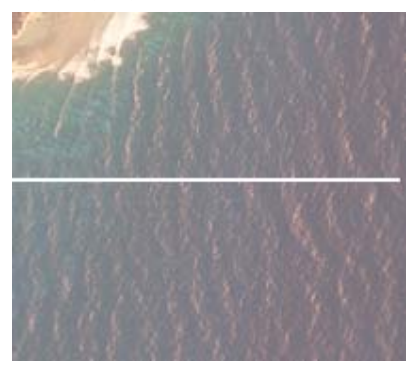

(a) (iv)

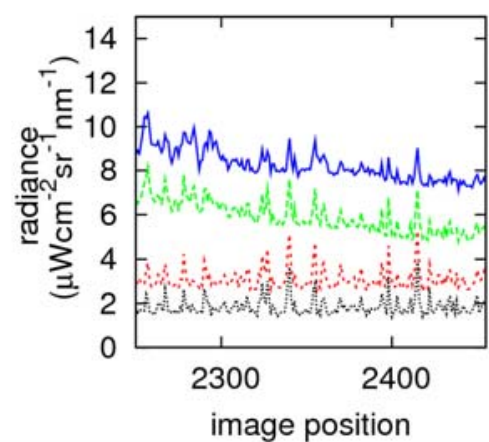

(b) (i)

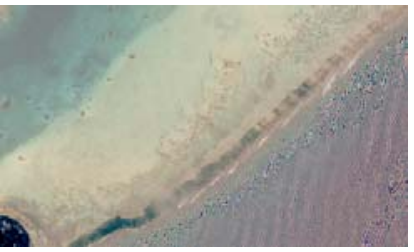

(b) (ii)

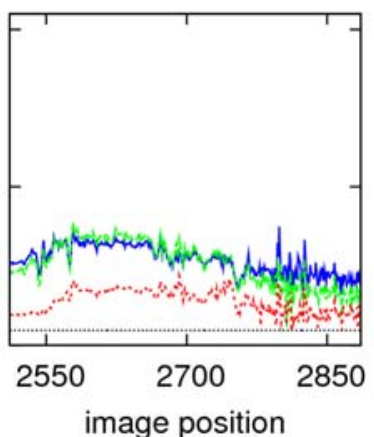

(b) (iii)

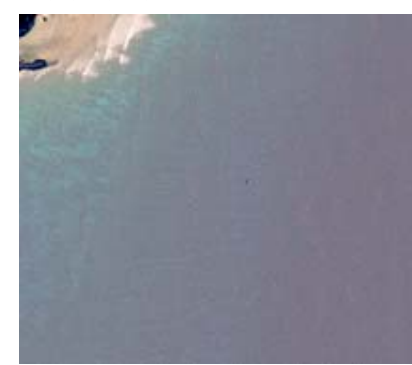

(b) (iv)

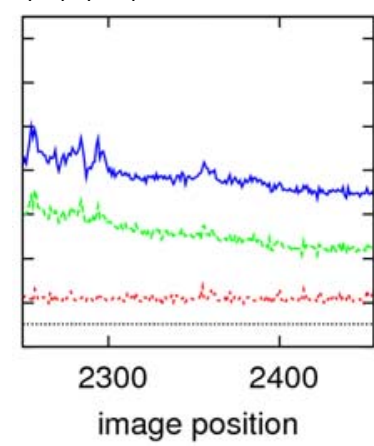

(c) (i)

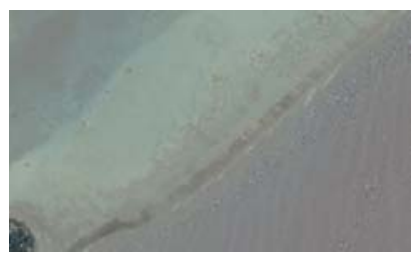

(c) (ii)

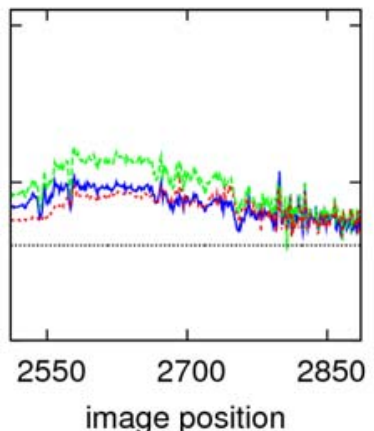

(c) (iii)

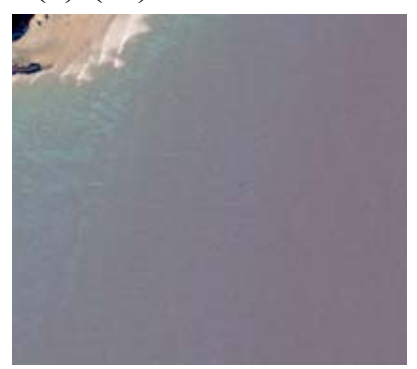

(c) (iv)

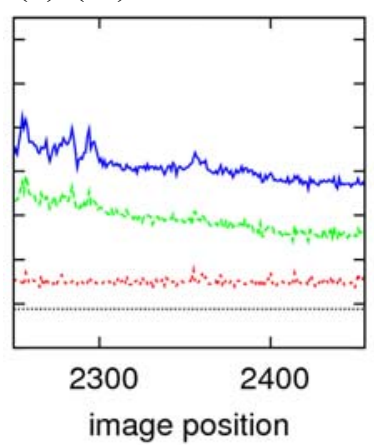

(d) (i)

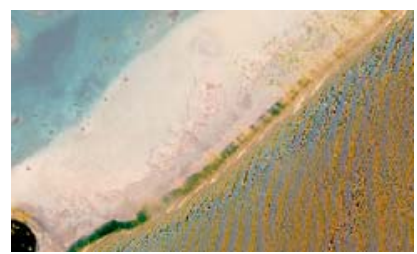

(d) (ii)

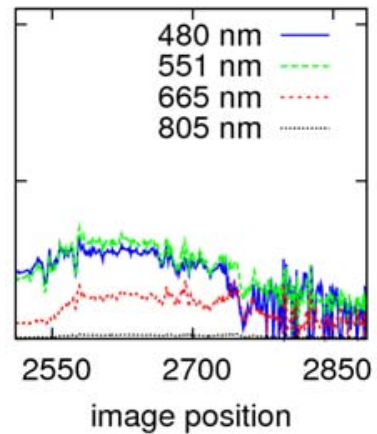

(d) (iii)

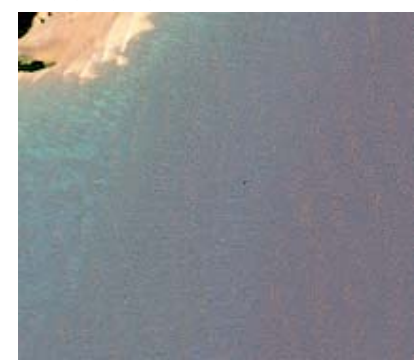

(d) (iv)

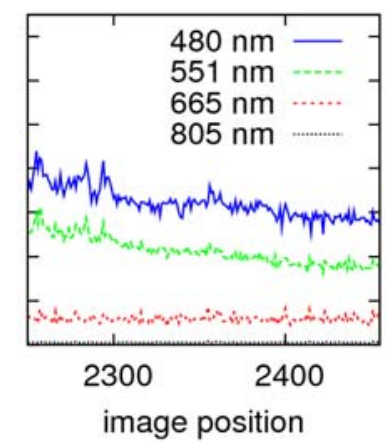

The effects of the Hedley and Lyzenga methods are similar, though corrected radiances in the Hedley method are lower, because the NIR values are taken towards the minimum value, rather than 
the mean in the Lyzenga method - these values are shown by the straight lines for the NIR in the IKONOS graphs [Figure 8 (b), (c)]. In the CASI graphs, Figure 7, the NIR waveband plotted (781 nm) is not the one that was used for the correction $(851 \mathrm{~nm})$ so the line shows some variation. In the IKONOS graphs there are also some differences in the relative intensity of the different wavebands for the Hedley and Lyzenga methods - this is possible because the correction factor is different for each waveband, whereas in the Goodman method the same correction is applied to all bands at a given pixel.

The Goodman method can only be used approximately with the IKONOS data, as only 4 wavebands are available. The correction has been applied using the 665 and $805 \mathrm{~nm}$ wavebands, instead of 640 and $750 \mathrm{~nm}$. This may account for the color distortion that is apparent in Figure 8(d) (i) and the relatively high residual noise in the radiances [Figure 8 (d) (ii)]. It was more successful for the less contaminated image, [Figure 8(d) (iii), (iv)].

One use of this type of imagery is to categorize sub-surface features by statistical classification techniques that group together similar looking pixels, for example [2,34]. Glint and noise can both change the spectral signature of a pixel and lead to misclassification. In this case the relative magnitude and shape of the radiance profiles is more important than absolute radiometric accuracy - the best method will reduce noise to a minimum, as well as removing the glint.

Where physics-based inversion methods are used to derive information about water depth, water optical properties or sea bed reflectance the absolute values of the radiance are important [63]. All the methods described have been successfully used in this type of situation; a few examples are the Lyzenga method used for bathymetry [9], the Hedley method for benthic cover mapping and classification [65], the Goodman method for classification based on a semi-analytical optical model [66]. However, there have been few comparative studies. Goodman et al. [1] compared the effect of their method with the 2-pixel regression method of Hochberg et al. [2], using AVIRIS imagery which was contaminated by cross-track glint. Depths derived from processed data were compared to Lidar bathymetry. The Goodman method performed better, with correlation coefficients of 0.795 to 0.912 depending on the atmospheric correction methods used. The method of Hochberg et al. gave correlations of -0.253 to 0.780 and data with no glint correction gave -0.131 to 0.894 . Goodman et al. deduce that pixel-by pixel methods work better than regression methods for data that has significant cross-track glint contamination. In the CASI image (Figure 7) the reverse seems to be true, with more glint remaining in (d) than in (b) or (c). The regression methods bring the glint-and no-glint pixels into better agreement across the wavelength range, while the pixel-by-pixel method has left some glint contamination at around 500nm. However, the values of A and B were those used for the AVIRIS sensor, with A rescaled to allow for the difference in measurement units - it may be possible to achieve better results by optimizing A and B for CASI. The differences may also be connected to the different spatial scales of the images, with cross-track glint occurring over a longer distance than wave-scale glint.

It is not yet clear which method will give the best results in any given situation, and researchers are advised to try a variety of methods before deciding which will work best with their data. 


\subsection{Limitations of These Methods}

All of the above methods rest on the assumption that all near-infrared radiation is absorbed by water, and hence the water-leaving radiance will be zero. How accurate that assumption is depends on the local conditions - for example in shallow or turbid water infrared radiation can be reflected back into the air by the seabed or sediment before it has been absorbed. Hooker et al. [67] suggest that the assumption is accurate for different wavelengths, depending on the circumstances: for the open ocean $\lambda=670 \mathrm{~nm}$ is long enough (from [68]), for all other phytoplankton-dominated (Case 1) waters $\lambda=765 \mathrm{~nm}$ or $865 \mathrm{~nm}$ is adequate [24], for waters with other particulate or dissolved matter (Case 2) $\lambda=1,012 \mathrm{~nm}$ is needed [69]. Tank experiments confirm that suspended particles can significantly affect NIR reflectance at $865 \mathrm{~nm}$ and shorter [26], leading to a non-zero NIR signal from below the surface.

Regression based methods are not dependent on the zero-NIR assumption for establishing the regression slope, but some method for estimating the water-leaving NIR is required to apply the correction. How this is handled is the only difference between the methods of Hedley et al. [10], Lyzenga et al. [9] and Joyce [64]. For routine application to a large number of images an automated procedure to select a deep water area would be helpful. A weakness of these methods is that they assume that the relationship between visible and NIR wavelengths found for the deep water area will hold for the rest of the image - this may not be true if the atmospheric properties are not uniform. The Goodman method does allow for cross-scene variation, as each pixel is corrected independently, but it makes the same correction for each wavelength. A wavelength dependent, pixel-by-pixel method might perform better.

All of the methods used in this section carry out atmospheric processing separately from the glint correction. For satellite data atmospheric correction is usually done first, so if the aerosol correction has not been accurately made this can affect the estimation of glint (Sections 2.1, 4.4, 5.2). The CASI data used for Figure 7 had no atmospheric correction; for airborne instruments atmospheric effects are less important, but there is still scope for uncorrected radiance from aerosol scattering to affect the glint correction. As with the open-ocean methods, improvements could be made by physics-based methods that model radiative transfer processes in the air, in the water and at the air-water interface.

\section{Wavelengths Outside the Visible and NIR}

While this review has focused on the problems of sun glint at visible wavelengths, glint can also be a problem for remote sensing methods using infrared and microwave wavelengths. Zavody and Birks [70] analyzed the effect of glint on infrared measurements for sea surface temperature (SST) derivation, as measured by the ATSR-2 sensor. They concluded that strong sun glint could increase the measured brightness temperature by $0.2 \mathrm{~K}$ or more, leading to errors in SST of up to about $0.5 \mathrm{~K}$. They suggest a correction algorithm: the calculated brightness temperature is changed by a factor proportional to the measured reflectivity and dependent on the water vapor. They stress this would need to be done again for different sensors because the analysis depends on viewing angle and polarization effect. They also note that some (small) confounding factors may still be presentmeasured glint is higher than that computed by the model. Simpson et al. [71] note that glint can be 
mistaken for cloud when analyzing infrared radiometry data. This leads to a loss of information since SST cannot be assessed in cloud areas, but can be retrieved from glint zones as long as only the far thermal infrared bands (11-12 $\mu \mathrm{m})$ are used: it is the NIR bands that are likely to be contaminated by glint as they comprise a much greater component of solar radiation. They propose a novel method, based on a neural network, that can distinguish between open ocean, glint and cloud more accurately than an existing cloud mask that predicts glint regions using the Cox and Munk model.

Salinity sensors use L-band microwave radiometry to measure the emissivity of the sea surface and hence find the dielectric constant of the water. This requires high accuracy and hence is susceptible to contamination by glint. Dinnat and Le Vine [72] assessed the extent of the problem for the Aquarius radiometer due to be launched in 2010. The satellite orbit will follow the day/night line and although the design keeps the antenna in darkness and avoids specular reflection from a flat sea, the effect of rough sea surfaces will be to reflect some solar radiation into the instrument. A two scale model of the sea surface suggests that glint effects could lead to an error in brightness temperature up to $0.05 \mathrm{~K}$, while the measurements must be accurate to $0.1 \mathrm{~K}$ to retrieve sea surface salinity measurements to within 0.2 practical salinity units. A study for the SMOS instrument [73] suggests similar problems, with radiation scattered from rough seas leading to measurement errors of up to $0.2 \mathrm{~K}$, corresponding to an error in salinity of 0.5 practical salinity units or more. Therefore, glint assessment is likely to be needed on both missions, with contaminated pixels flagged.

\section{Useful Glint}

It is worth noting that sun glint information in the visible and NIR wavelengths can also be a useful source of data in its own right. For example, it can be used to cross-calibrate different wavebands [74-76] or to give information about the atmosphere [77,78]. It can, as in the original study of Cox and Munk [4,5,30], give information about the state of the sea surface [48,79], and can also reveal internal waves within the ocean [80]. Thus, if the glint radiance can be accurately found it could yield useful results in itself as well as enabling corrections to be made and hence allowing increased accuracy of retrieval of below-surface conditions.

\section{Summary and Prospects for Further Development}

Two categories of method for correcting sun glint in optical images of the sea have been reviewed, those using predictions of reflection based on a model of the sea surface and those that use in-scene information with the assumption of no NIR water-leaving radiance. The first category of method is used for operational ocean color data processing at spatial resolutions of 100-1,000 m, while the second has been applied to high resolution images of coral reefs and other shallow waters with pixel sizes of around 1-10 m. Both methods have been successful in increasing the proportion of data that can be retrieved from ocean and coastal sensors, but there is potential for further improvement.

NIR methods similar to those described in Section 5 are currently used for atmospheric correction in the ocean color instruments [25]. The NIR could also give information about sun glint, if a way can be found to separate the effects of the aerosol scattering, water-leaving radiance and glint. This is the aim of the neural network methods currently being developed (Section 4.5). By their nature, neural network approaches do not give any insight into the physical processes at work, and another way forward will 
be to use physics-based methods that model the transfer of radiation through the air, water and airwater interface.

There is also scope for synthesis of the large scale statistical approach with the high spatial resolution NIR based methods. Statistical approaches could be used to constrain the expected glint component over areas to which high-resolution NIR methods are applied. This may help to estimate the water-leaving NIR component. However in shallow water areas where the high spatial resolution methods are most commonly used, the sea surface state is most likely to deviate from an open ocean statistical model.

The radiative transfer models used in current glint correction schemes include a limited number of processes, and there is scope to improve the models by building in multiple scattering, polarization, multiple reflection at the water surface and the shadowing effects of large waves. Current algorithms use the Cox and Munk statistics of the sea surface [4] but without simulating the sea surface shape: recent wave elevation spectra $[81,82]$ could be used to model the interaction of light with more realistically simulated sea surfaces. For shallow and turbid waters, radiative transfer modeling, along with lab and field experiments, is needed to give us more information about the transfer of NIR radiation.

Global monitoring of the world's oceans, coasts and coral reefs is an essential part of our response to climate change. Better methods for sun glint correction will enable more data to be retrieved from existing and future missions, with improved accuracy, and give us greater confidence in our understanding of the marine environment.

\section{Acknowledgments}

This work was undertaken as part of a project supported by ARGANS Ltd and Great Western Research. J Hedley is funded by the Natural Environment Research Council.

Figure 1a and Figure 5 Data provided by the European Space Agency.

Figure 1c and Figure 8 (C) 2003, European Space Imaging GmbH, all rights reserved.

Figure 1e and Figure 7 based on digital spatial data licensed from the Natural Environment Research Council CNERC 1998.

\section{References and Notes}

1. Goodman, J.A.; Lee, Z.; Ustin, S.L. Influence of Atmospheric and Sea-Surface Corrections on Retrieval of Bottom Depth and Reflectance Using a Semi-Analytical Model: A Case Study in Kaneohe Bay, Hawaii. Appl. Opt. 2008, 47, F1-F11.

2. Hochberg, E.; Andrefouet, S.; Tyler, M. Sea Surface Correction of High Spatial Resolution Ikonos Images to Improve Bottom Mapping in Near-Shore Environments. IEEE Trans. Geosci. Remote Sens. 2003, 41, 1724-1729.

3. Steinmetz, F.; Deschamps, P.; Ramon, D. Atmospheric Correction in Presence of Sun Glint: Application to MERIS. Presented at the 2nd MERIS-(A)ATSR workshop, Frascati, Italy 22-26 September 2008; Available online: http://earth.esa.int/cgi-bin/confm8.pl?abstract $=75$ (accessed 17 December 2008). 
4. Cox, C.; Munk, W. Statistics of the Sea Surface Derived from Sun Glitter. J. Mar. Res. 1954, 13, 198-227.

5. Cox, C.; Munk, W. Measurement of the Roughness of the Sea Surface from Photographs of the Suns Glitter. J. Opt. Soc. Am. 1954, 44, 838-850.

6. Wang, M.; Bailey, S. Correction of Sun Glint Contamination on the SeaWiFS Ocean and Atmosphere Products. Appl. Opt. 2001, 40, 4790-4798.

7. Montagner, F.; Billat, V.; Belanger, S. MERIS ATBD 2.13 Sun Glint Flag Algorithm. Available online: http://envisat.esa.int/instruments/meris/atbd/atbd_2_13.pdf (accessed 5 November 2008).

8. Gordon, H.; Voss, K. MODIS Normalized Water-Leaving Radiance Algorithm Theoretical Basis Document (MOD 18), Version 5; NASA: Washington, DC, 2004. Available online: http://modis.gsfc. nasa.gov/data/atbd/atbd_mod18.pdf (accessed 19 March 2009).

9. Lyzenga, D.; Malinas, N.; Tanis, F. Multispectral Bathymetry Using a Simple Physically Based Algorithm. IEEE Trans. Geosci. Remote Sens. 2006, 44, 2251-2259.

10. Hedley, J.; Harborne, A.; Mumby, P. Simple and Robust Removal of Sun Glint for Mapping Shallow-Water Benthos. Int. J. Remote Sens. 2005, 26, 2107-2112.

11. SeaWiFS Project - Homepage. http://oceancolor.gsfc.nasa.gov/SeaWiFS/ (accessed 6 May 2009).

12. Earth Observation Satellite - Global Imager. http://www.eorc.jaxa.jp/en/hatoyama/satellite/sendata/ gli_e.html (accessed 6 May 2009).

13. ESA Earthnet: The Medium Resolution Imaging Spectrometer Instrument. http://envisat.esa.int/object /index.cfm?fobjectid=1665 (accessed 6 May 2009).

14. MODIS Website. http://modis.gsfc.nasa.gov/about/ (accessed 6 May 2009).

15. GeoEye - IKONOS. http://www.geoeye.com/CorpSite/products/imagery-sources/Default.aspx\#ikonos (accessed 6 May 2009).

16. AVIRIS Home Page. http://aviris.jpl.nasa.gov/ (accessed 6 May 2009).

17. NERC Airborne Research and Survey Facility - CASI. http://arsf.nerc.ac.uk/instruments/casi.asp (accessed 6 May 2009).

18. NASA - Coastal Zone Color Scanner. http://nssdc.gsfc.nasa.gov/nmc/experimentDisplay.do?id= 1978-098A-03 (accessed 6 May 2009).

19. Earth Observation Satellite - Ocean Color and Temperature Sensor. http://www.eorc.jaxa.jp/en/ hatoyama/satellite/sendata/octs_e.html (accessed 6 May 2009).

20. Earth Observation Satellite - Polarization and Directionality of the Earth's Reflectances. http://www.eorc.jaxa.jp/ en/hatoyama/satellite/sendata/polder_e.html (accessed 6 May 2009).

21. ESA - Living Planet Programme - GMES - Sentinel-3. http://www.esa.int/esaLP/SEMTST4KXMF_ LPgmes_0.html (accessed 5 May 2009).

22. Sturm, B. The Atmospheric Correction of Remotely Sensed Data and the Quantitative Determination of Suspended Matter in Marine Water Surface Layers. In Remote Sensing in Meteorology, Oceanography and Hydrology; Cracknell, A.P., Ed; Ellis Horwood Ltd: Chichester, UK, 1981; pp. 163-197.

23. Mobley, C.D. Light and Water: Radiative Transfer in Natural Waters; Academic Press: San Diego, CA, USA; 1994.

24. Gordon, H.; Wang, M. Retrieval of Water-Leaving Radiance and Aerosol Optical-Thickness Over the Oceans with Seawifs - a Preliminary Algorithm. Appl. Opt. 1994, 33, 443-452. 
25. Siegel, D.A.; Wang, M.; Maritorena, S.; Robinson, W. Atmospheric Correction of Satellite Ocean Color Imagery: The Black Pixel Assumption. Appl. Opt. 2000, 39, 3582-3591.

26. Lavender, S.; Pinkerton, M.; Moore, G.; Aiken, J.; Blondeau-Patissier, D. Modification to the Atmospheric Correction of SeaWiFS Ocean Colour Images Over Turbid Waters. Cont. Shelf Res. 2005, 25, 539-555.

27. Hale, G.; Querry, M. Optical-Constants of Water in 200-Nm to 200-Mum Wavelength Region. Appl. Opt. 1973, 12, 555-563.

28. Quan, X.; Fry, E. S. Empirical Equation for the Index of Refraction of Seawater. Appl. Opt. 1995, $34,3477-3480$.

29. Smirnov, A.; Holben, B.N.; Kaufman, Y.J.; Dubovik, O.; Eck, T.F.; Slutsker, I.; Pietras, C.; Halthorne, R.N. Optical Properties of Atmospheric Aerosol in Maritime Environments. J. Atmos. Sci. 2002, 59, 501-523.

30. Cox, C.; Munk, W. Slopes of the Sea Surface Deduced from Photographs of Sun Glitter. Scripps Inst. Oceanogr. Bull. 1956, 6, 401-488.

31. Wang, M.; Isaacman, A.; Franz, B.; McClain, C. Ocean-Color Optical Property Data Derived from the Japanese Ocean Color and Temperature Scanner and the French Polarization and Directionality of the Earth's Reflectances: A Comparison Study. Appl. Opt. 2002, 41, 974-990.

32. Gordon, H.; Wang, M. Surface-Roughness Considerations for Atmospheric Correction of Ocean Color Sensors. 1. The Rayleigh-Scattering Component. Appl. Opt. 1992, 31, 4247-4260.

33. Seawifs Overflight Prediction Information. http://oceancolor.gsfc.nasa.gov/SUPPORT/Overflight_Info.html (accessed 5 May 2009).

34. Wolter, P.; Johnston, C.; Niemi, G. Mapping Submergent Aquatic Vegetation in the US Great Lakes Using Quickbird Satellite Data. Int. J. Remote Sens. 2005, 26, 5255-5274.

35. Dekker, A.; Byrne, G.; Brando, V.; Anstee, J. Hyperspectral Mapping of Intertidal Rock Platform Vegetation as a Tool for Adaptive Management; CSIRO Land and Water: Canberra, Australia, 2003.

36. Mustard, J.; Staid, M.; Fripp, W. A Semianalytical Approach to the Calibration of AVIRIS Data to Reflectance Over Water Application in a Temperate Estuary. Remote Sens. Environ. 2001, 75, 335-349.

37. Mobley, C. Estimation of the Remote-Sensing Reflectance from Above-Surface Measurements. Appl. Opt. 1999, 38, 7442-7455.

38. Philpot, W. Estimating Atmospheric Transmission and Surface Reflectance from a GlintContaminated Spectral Image. IEEE Trans. Geosci. Remote Sens. 2007, 45, 448-457.

39. Mount, R. Acquisition of Through-Water Aerial Survey Images: Surface Effects and the Prediction of Sun Glitter and Subsurface Illumination. Photogramm. Eng. Rem. S. 2005, 71, 1407-1415.

40. Fukushima, H.; Toratani, M.; Murakami, H.; Deschamps, P.; Frouin, R.; Tanaka, A. Evaluation of ADEOS-II GLI Ocean Color Atmospheric Correction Using SIMBADA Handheld Radiometer Data. J. Oceanogr. 2007, 63, 533-543.

41. Ottaviani, M.; Spurr, R.; Stamnes, K.; Li, W.; Su, W.; Wiscombe, W. Improving the Description of Sunglint for Accurate Prediction of Remotely Sensed Radiances. J. Quant. Spectrosc. Radiat. Transf. 2008, 109, 2364-2375. 
42. Doerffer, R.; Schiller, H.; Fischer, J.; Preusker, R.; Bouvet, M. The Impact of Sun Glint on the Retrieval of Water Parameters and Possibilities for the Correction of MERIS Scenes. In Proceedings of the 2nd MERIS-(A)ATSR workshop, Frascati, Italy, September 22-26, 2008.

43. Kutser, T.; Vahtmäe, E.; Praks, J.A. Sun Glint Correction Method for Hyperspectral Imagery Containing Areas with Non-Negligible Water Leaving NIR Signal. Remote Sens. Environ. 2009, 113, 2267-2274.

44. Munk, W. An Inconvenient Sea Truth: Spread, Steepness, and Skewness of Surface Slopes. Annu. Rev. Mar. Sci. 2009, 1, 377-415.

45. Plant, W. A New Interpretation of Sea-Surface Slope Probability Density Functions. J. Geophys. Res. 2003, 108, C9, 3295, 11:1-11:4.

46. Wu, J. Mean-Square Slopes of the Wind-Disturbed Water-Surface, Their Magnitude, Directionality, and Composition. Radio Sci. 1990, 25, 37-48.

47. Fukushima, H.; Suzuki, K.; Li, L.; Suzuki, N.; Murakami, H. Improvement of the ADEOS-II/GLI Sun-Glint Algorithm Using Concomitant Microwave Scatterometer-Derived Wind Data. Adv. Space Res. 2009, 43, 941-947.

48. Ebuchi, N.; Kizu, S. Probability Distribution of Surface Wave Slope Derived Using Sun Glitter Images from Geostationary Meteorological Satellite and Surface Vector Winds from Scatterometers. J. Oceanogr. 2002, 58, 477-486.

49. Bréon, F.; Henriot, N. Spaceborne Observations of Ocean Glint Reflectance and Modeling of Wave Slope Distributions. J. Geophys. Res. 2006, 111, C06005:1-C06005:10.

50. Fox, D.; Gonzalez, E.; Kahn, R.; Martonchik, J. Near-Surface Wind Speed Retrieval from Space-Based, Multi-Angle Imaging of Ocean Sun Glint Patterns. Remote Sens. Environ. 2007, 107, 223-231.

51. Gatebe, C.; King, M.; Lyapustin, A.; Arnold, G.; Redemann, J. Airborne Spectral Measurements of Ocean Directional Reflectance. J. Atmos. Sci. 2005, 62, 1072-1092.

52. SeaDAS Home Page. http://oceancolor.gsfc.nasa.gov/seadas/ (accessed 5 May 2009).

53. Franz, B. Overview of MODIS Processing Within The Ocean Color Discipline Processing System (OCDPS). NASA: Washington, DC, June 2003; Available online: http://oceancolor.gsfc.nasa.gov/ DOCS/modis_processing_overview.pdf (accessed 10 March 2009).

54. Ocean Color Announcement. http://oceancolor.gsfc.nasa.gov/forum/oceancolor/topic_show.pl?tid=356 (accessed 8 May 2009).

55. ACRI. MERIS Level 1 Detailed Processing Model. Available online: http://earth.esa.int/pub/ ESA_DOC/ENVISAT/MERIS/MERIS_DPML1b_i7r1.pdf (accessed 26 February 2009).

56. ACRI. MERIS Level 2 Detailed Processing Model. Available online: http://earth.esa.int/pub/ESA_DOC/ ENVISAT/MERIS/MERIS_DPML2_i7r2A_re-issued.pdf(accessed 26 February 2009).

57. Hwang, P.; Shemdin, O. The Dependence of Sea-Surface Slope on Atmospheric Stability and Swell Conditions. J. Geophys. Res. 1988, 93, 13903-13912.

58. Shaw, J.; Churnside, J. Scanning-Laser Glint Measurements of Sea-Surface Slope Statistics. Appl. Opt. 1997, 36, 4202-4213.

59. Hwang, P. A. Observations of Swell Influence on Ocean Surface Roughness. J. Geophys. Res. 2008, 113, C12024:1-C12024:14. 
60. Fischer, J.; Preusker, R.; Doerffer, R.; Bouvet, M. Atmospheric Correction of Sun Glint Contaminated MERIS Observations. In Proceedings of the 2nd MERIS-(A)ATSR workshop, Frascati, Italy, September 22-26, 2008.

61. Heege, T.; Fischer, J. Sun Glitter Correction in Remote Sensing Imaging Spectrometry. In Proceedings of SPIE Ocean Optics XV Conference, Monaco, October 16-20, 2000.

62. Carder, K.; Steward, R. A Remote-Sensing Reflectance Model of a Red-Tide Dinoflagellate Off West Florida. Limnol. Oceanogr. 1985, 30, 286-298.

63. Lee, Z.; Carder, K.; Mobley, C.; Steward, R.; Patch, J. Hyperspectral Remote Sensing for Shallow Waters: 2. Deriving Bottom Depths and Water Properties by Optimization. Appl. Opt. 1999, 38, 3831-3843.

64. Joyce, K.E. A Method for Mapping Live Coral Cover Using Remote Sensing. Ph.D. thesis, University of Queensland: Brisbane, Australia, 2004.

65. Bertels, L.; Vanderstraete, T.; van Coillie, S.; Knaeps, E.; Sterckx, S.; Goossens, R.; Deronde, B. Mapping of Coral Reefs Using Hyperspectral CASI Data; a Case Study: Fordata, Tanimbar, Indonesial. Int. J. Remote Sens. 2008, 29, 2359-2391.

66. Goodman, J.; Ustin, S. Classification of Benthic Composition in a Coral Reef Environment Using Spectral Unmixing. J. Appl. Remote Sens. 2007, 1, 011501:1-011501:17

67. Hooker, S.; Lazin, G.; Zibordi, G.; McLean, S. An Evaluation of Above- and in-Water Methods for Determining Water-Leaving Radiances. J. Atmos. Ocean. Tech. 2002, 19, 486-515.

68. Gordon, H.R. A Preliminary Assessment of the Nimbus-7 CZCS Atmospheric Correction Algorithm in a Horizontally Inhomogeneous Atmosphere. In Oceanography from Space, Gower, J.F.R., Ed.; Plenum Press: New York, NY, USA, 1981; pp. 257-266.

69. Bukata, R.P.; Jerome, J.H.; Kondrattyev, K.Y.; Pozdnyakov, D.V. Optical Properties and Remote Sensing of Inland and Coastal Waters; CRC Press: Boca Raton, FL, USA, 1995.

70. Zavody, A.; Birks, A. Sun Glint Contamination in ATSR-2 Data: Comparison of Observations and Values Calculated from the Measured 1.6-Mu M M Reflectivities. J. Atmos. Ocean. Tech. 2004, 21, 787-798.

71. Simpson, J.; Tsou, Y.; Schmidt, A.; Harris, A. Analysis of Along Track Scanning Radiometer-2 (ATSR-2) Data for Clouds, Glint and Sea Surface Temperature Using Neural Networks. Remote Sens. Environ. 2005, 98, 152-181.

72. Dinnat, E.; Le Vine, D. Impact of Sun Glint on Salinity Remote Sensing: An Example with the Aquarius Radiometer. IEEE Trans. Geosci. Remote Sens. 2008, 46, 3137-3150.

73. Reul, N.; Tenerelli, J.; Chapron, B.; Waldteufel, P. Modeling Sun Glitter at L-Band for Sea Surface Salinity Remote Sensing with SMOS. IEEE Trans. Geosci. Remote Sens. 2007, 45, 2073-2087.

74. Zavody, A.; Watts, P.; Smith, D.; Mutlow, C. A Novel Method for Calibrating the ATSR-2 1.6-Mu M Channel Using Simultaneous Measurements Made in the 3.7-Mu M Channel in Sun Glint. $J$. Atmos. Ocean. Tech. 1998, 15, 1243-1252.

75. Hagolle, O.; Nicolas, J.; Fougnie, B.; Cabot, F.; Henry, P. Absolute Calibration of VEGETATION Derived from an Interband Method Based on the Sun Glint Over Ocean. IEEE Trans. Geosci. Remote Sens. 2004, 42, 1472-1481. 
76. Nicolas, J.; Deschamps, P.; Hagolle, O. Radiometric Calibration of the Visible and Near-Infrared Bands of SEVIRI Using Rayleigh Scattering and Sun-Glint Over Oceans. In Proceedings of the 3rd MSG RAO Workshop, Helsinki, Finland, June 15, 2006, pp. 19-24.

77. Aoki, T.; Aoki, T.; Fukabori, M. Path-Radiance Correction by Polarization Observation of Sun Glint Glitter for Remote Measurements of Tropospheric Greenhouse Gases. Appl. Opt. 2002, 41, 4945-4957.

78. Gao, B.; Kaufman, Y. Water Vapor Retrievals Using Moderate Resolution Imaging Spectroradiometer (MODIS) Near-Infrared Channels. J. Geophys. Res. 2003, 108, D13, 4389 ACH 4-1 to 4-10.

79. Ross, V.; Dion, D. Sea Surface Slope Statistics Derived from Sun Glint Radiance Measurements and Their Apparent Dependence on Sensor Elevation. J. Geophys. Res. 2007, 112, C09015:1-C09015:11.

80. Jackson, C. Internal Wave Detection Using the Moderate Resolution Imaging Spectroradiometer (MODIS). J. Geophys. Res. 2007, 112, C11012:1-C11012:13.

81. Elfouhaily, T.; Chapron, B.; Katsaros, K.; Vandemark, D. A Unified Directional Spectrum for Long and Short Wind-Driven Waves. J. Geophys. Res. 1997, 102, 15781-15796.

82. Heron, M.; Skirving, W.; Michael, K. Short-Wave Ocean Wave Slope Models for Use in Remote Sensing Data Analysis. IEEE Trans. Geosci. Remote Sens. 2006, 44, 1962-1973.

(C) 2009 by the authors; licensee Molecular Diversity Preservation International, Basel, Switzerland. This article is an open-access article distributed under the terms and conditions of the Creative Commons Attribution license (http://creativecommons.org/licenses/by/3.0/). 